\title{
Air-Broadened Half-Widths of the 22- and 183-GHz Water-Vapor Lines
}

\author{
Vivienne H. Payne, Jennifer S. Delamere, Karen E. Cady-Pereira, Robert R. Gamache, \\ Jean-Luc Moncet, Eli J. Mlawer, and Shepard A. Clough
}

\begin{abstract}
Air-broadened half-widths of the 22- and 183-GHz water-vapor lines and associated uncertainties have been determined using comparisons between ground-based radiometric measurements from Atmospheric Radiation Measurement sites in Oklahoma and Alaska, and MonoRTM, a radiative transfer model. Values of the widths obtained using the measurements are $0.0900 \mathrm{~cm}^{-1} / \mathrm{atm}$ with $1.6 \%$ uncertainty for the $22-\mathrm{GHz}$ line and $0.0992 \mathrm{~cm}^{-1} /$ atm with $2.4 \%$ uncertainty for the $183-\mathrm{GHz}$ line. Also presented are spectroscopic parameters for these lines from new calculations performed using the complex implementation of the Robert-Bonamy theory (CRB). The CRB values of the air-broadened widths are $0.0913 \mathrm{~cm}^{-1} /$ atm with $3 \%$ uncertainty and a temperature exponent of 0.755 for the $22-\mathrm{GHz}$ line and $0.0997 \mathrm{~cm}^{-1} / \mathrm{atm}$ with $3 \%$ uncertainty and a temperature exponent of 0.769 for the $183-\mathrm{GHz}$ line. The values for the air-broadened half-widths derived from the measurement/model comparisons show good agreement with the new CRB calculations. For future versions of MonoRTM, width values of 0.0900 and $0.0997 \mathrm{~cm}^{-1} / \mathrm{atm}$ are to be adopted with temperature dependences of 0.76 and 0.77 for the 22- and 183-GHz lines, respectively.
\end{abstract}

Index Terms-Microwave radiometry, satellite applications, water-vapor absorption, water-vapor retrieval.

\section{INTRODUCTION}

$\mathbf{T}$ HE 22.24- and 183.31-GHz water-vapor lines are two of the most important spectroscopic lines for remote sensing of the Earth's atmosphere. These lines are utilized by a wide variety of instruments that measure water vapor for atmospheric studies and weather prediction, including instruments at the surface (e.g., [1]-[4]), on high-altitude research aircraft (e.g., [5]-[7]) and on satellites (e.g., [8]-[10]). These measurements are used for retrievals of atmospheric water vapor and as input to data assimilation schemes. The accuracy of the retrievals and

Manuscript received June 25, 2007; revised December 7, 2007 and February 17, 2008. Current version published October 30, 2008. The work of R. R. Gamache was supported by the National Science Foundation (NSF) under Grant ATM-0242537. This work was supported in part by the Office of Biological and Environmental Research of the U.S. Department of Energy as part of the Atmospheric Radiation Measurement Program and in part by the Joint Center for Satellite Data Assimilation.

V. H. Payne, J. S. Delamere, K. E. Cady-Pereira, E. J. Mlawer, and S. A. Clough are with the Radiation and Climate Group, Atmospheric and Environmental Research, Inc., Lexington, MA 02421-3136 USA (e-mail: vpayne@aer.com; jdelamer@aer.com; kcadyper@aer.com; emlawer@ aer.com; sclough@aer.com).

R. R. Gamache is with the Department of Environmental, Earth, and Atmospheric Sciences, University of Massachusetts, Lowell, MA 01854 USA (e-mail: robert_gamache@uml.edu).

J.-L. Moncet is with the Remote Sensing Division, Atmospheric and Environmental Research, Inc., Lexington, MA 02421-3136 USA (e-mail: jmoncet@ aer.com).

Digital Object Identifier 10.1109/TGRS.2008.2002435 the forecasts from the assimilation schemes directly depend on the accuracy of the line parameters used as input to the relevant radiative transfer models.

The line parameters may be obtained from laboratory measurements, which are often quoted with low uncertainties. However, laboratory measurements of the air-broadened halfwidth of these water-vapor lines from different sources do not agree within the stated measurement errors. In this paper, measurements from ground-based radiometers situated at two Atmospheric Radiation Measurement (ARM) Program sites are used in conjunction with radiosonde profiles and a radiative transfer model to determine the value of the air-broadened halfwidths that are most consistent with the radiometric measurements and to provide a realistic estimate of the uncertainty associated with these values.

Radiosonde profiles are often considered "truth." However, inconsistencies between measurements by different types of profilers, or even in profiles recorded by the same type of instrument, have been repeatedly noted ([11] and references therein). For example, significant site-specific biases in humidity profiles were noted during the Tropical Ocean Global Atmosphere Coupled Ocean Atmosphere Experiment observations. The magnitude of these biases was such that it was necessary to develop correction algorithms, which used an independent surface humidity measurement [12]. Another example is the dry bias in Vaisala RS80 humidity profiles revealed during a longterm study at the ARM Southern Great Plains (SGP) site [11]. Determining the source of such inconsistencies and developing methods to remove them has been the focus of much research in recent years (e.g., [13]-[15]). Uncertainties in the radiosonde profiles result in considerable scatter in comparisons between measurements from ground-based radiometers and radiative transfer models using radiosonde profiles as input. Scaling the radiosonde profiles according to the total precipitable water vapor (PWV) retrieved from microwave radiometers in the 22-GHz region has been shown to be an effective approach [11]. In this paper, we use this scaling approach to reduce the scatter in model/measurement comparisons in order to derive information on the linewidths from the measurements. The $22-\mathrm{GHz}$ linewidth was determined using a ground-based radiometer from the SGP ARM site in central Oklahoma. The prevailing atmospheric conditions at the SGP site over the chosen time period were advantageous for the study of the $22-\mathrm{GHz}$ line. The $183-\mathrm{GHz}$ line parameters were determined using a radiometer situated at the North Slope of Alaska (NSA) ARM site. The drier conditions at the NSA are more appropriate for the study of this line, which becomes saturated under SGP conditions. 

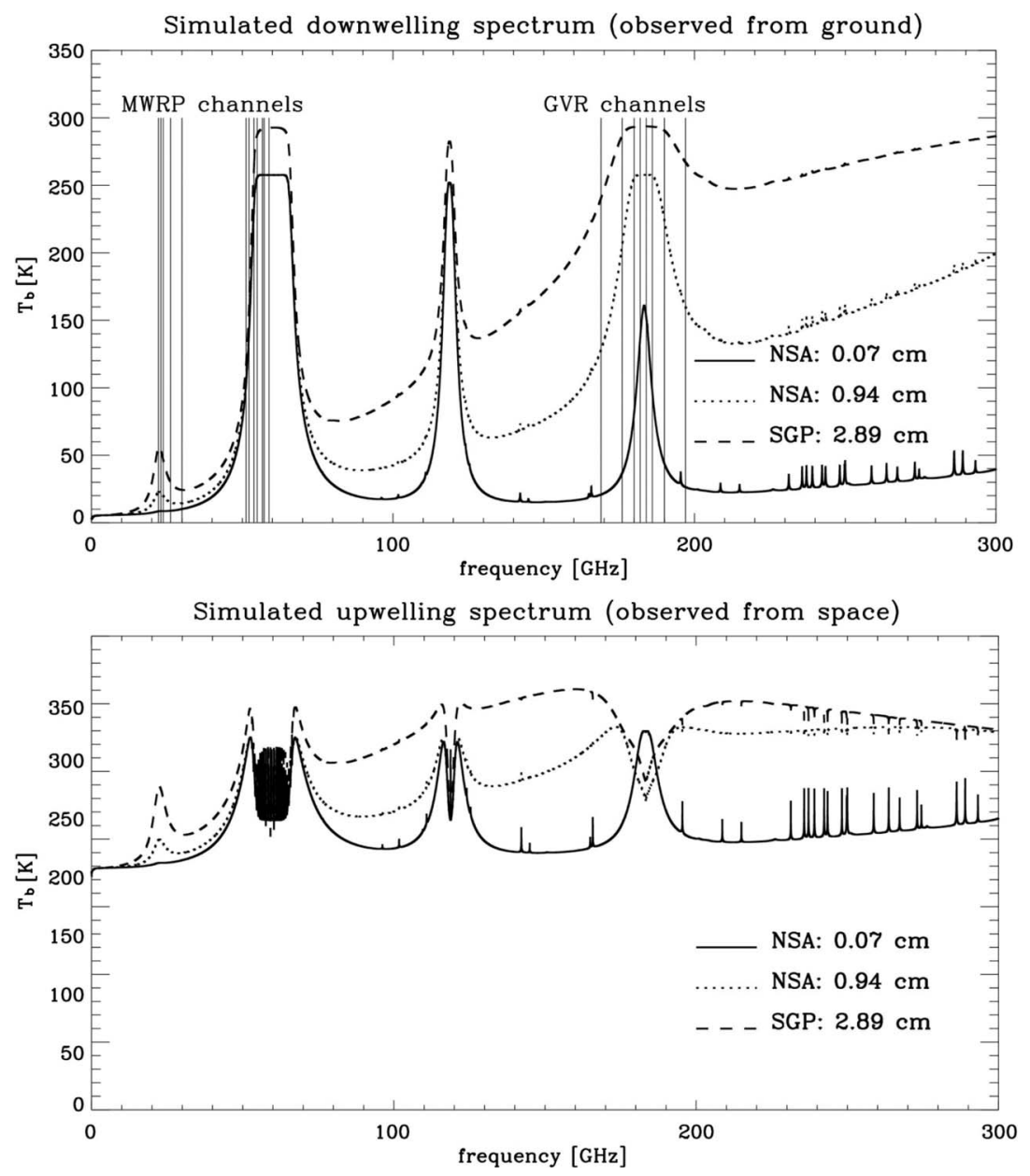

Fig. 1. Simulated (top) downwelling and (bottom) upwelling microwave brightness temperature spectra for different atmospheric conditions and column watervapor amounts. The positions of the channels of the two radiometers used in this paper (the MWRP at the SGP and the GVR at the NSA) are marked on the downwelling spectrum.

We also present new values for the air-broadened halfwidth, the temperature dependence of the half-width, and the pressure shift for the 22- and 183-GHz water-vapor lines from calculations performed using the complex implementation of the Robert-Bonamy theory (CRB). These values are considered in the context of the results from the comparisons between the radiative transfer model and the ground-based radiometers.

\section{Modeling WATER-VAPOR AbSORPtion IN THE MiCROWAVE}

\section{A. MonoRTM}

The radiative transfer model used in this paper is MonoRTM, a monochromatic model for the microwave region [16], [17]. The Humlicek Voigt line shape [18] is used for all pressure regimes. Effects of the duration of collision are included in the slow spectral dependence incorporated in the self and foreign broadened continuum. All relevant spectroscopic lines are included in the calculations in the general case. The continuum implemented in MonoRTM is the CKD_2.4 (CKD = Clough, Kneizys, and Davis), which in the microwave region is virtually identical to the MT_CKD continuum (MT = Mlawer and Tobin) [17]. MonoRTM uses a special spectro- scopic line file derived from High-resolution Transmission Molecular Absorption (HITRAN) 2000, with updates for certain lines. The dominant features in the microwave region (see Fig. 1) are the $22-\mathrm{GHz}$ water-vapor line, the $60-\mathrm{GHz}$ oxygen band, the $118-\mathrm{GHz}$ oxygen line, and the $183-\mathrm{GHz}$ water-vapor line. The oxygen linewidths and line mixing parameters in MonoRTM are from Tretyakov et al. [19], [20]. The line strengths for the 22- and 183-GHz water-vapor transitions are from [21]. These strengths were obtained from measurements of the Stark effect and are known to within $0.5 \%$ (the limiting error in the Stark experiments is in the magnitude of the electrical field which is extremely small). The strength values used equate to $4.348 \mathrm{e}^{-25}$ and $7.691 \mathrm{e}^{-23} \mathrm{~cm}^{-1} /\left(\right.$ molecule $\left.\cdot \mathrm{cm}^{-2}\right)$ at $296 \mathrm{~K}$ for the $22-$ and $183-\mathrm{GHz}$ lines, respectively. The values used for the width of the 22- and $183-\mathrm{GHz}$ water-vapor lines are critically important for measurements of atmospheric water vapor and cloud liquid water (CLW) and are the subject of this paper.

Fig. 2 and Tables I and II show published values of the air-broadened half-widths at $296 \mathrm{~K}$ with quoted uncertainties [22]-[40]. Also shown are width values for the equivalent transitions in the $\mathrm{H}_{2} \mathrm{O} \nu_{2}$ band in the infrared. Laboratory measurements for the widths of these infrared transitions have extensively been validated, are reported to be known to high 

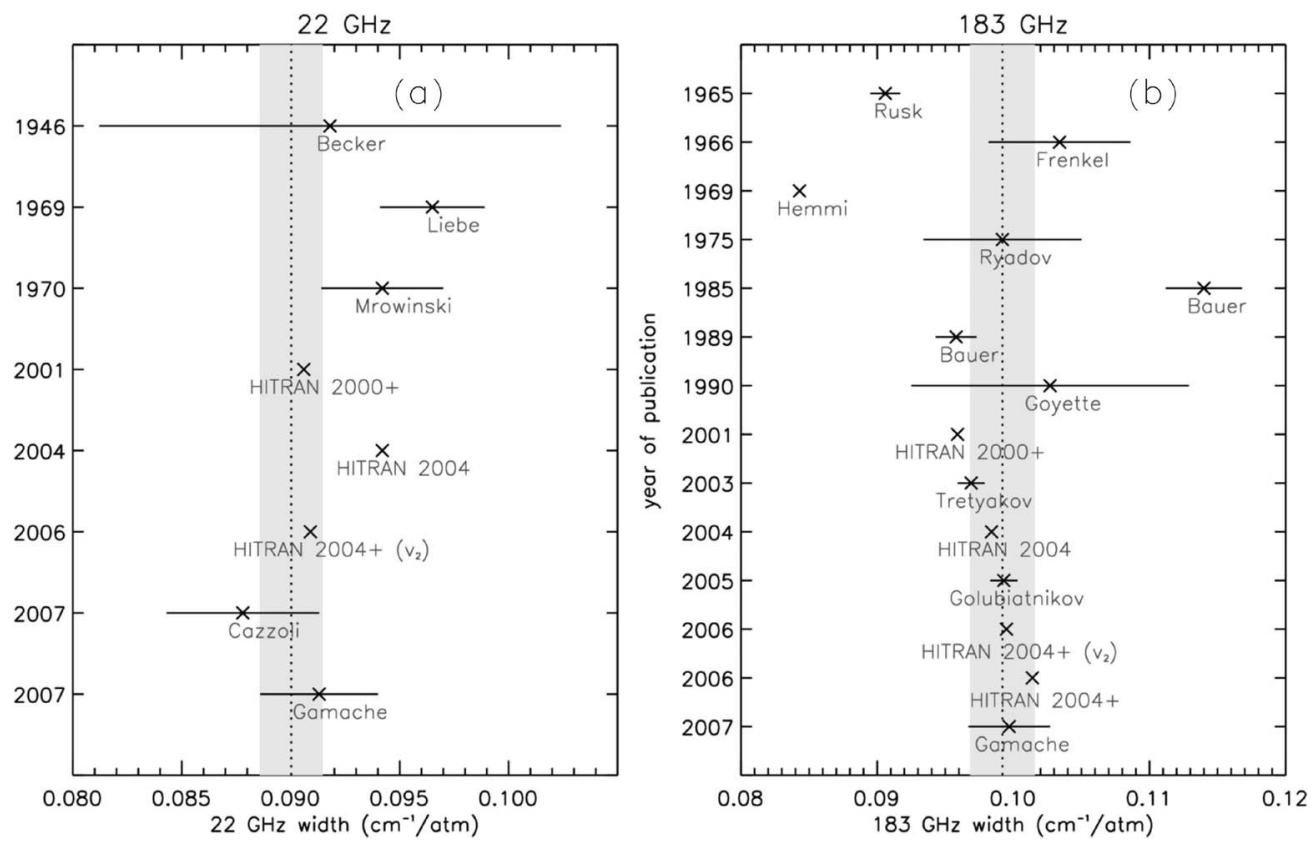

Fig. 2. Air-broadened half-widths of (a) the 22- and (b) the 183-GHz lines: laboratory measurements, calculations, and values from recent versions of the HITRAN database, displayed in order of publication. The vertical dotted lines represent the values obtained in this paper using the MWRP (22 GHz) and GVR $(183 \mathrm{GHz})$ measurements, while the shaded bars represent the error bounds for these values.

TABLE I

Air-Broadened Half-Widths $(\gamma)$ of the 22-GHz Water-Vapor Line From Laboratory Measurements, Calculations and From Recent

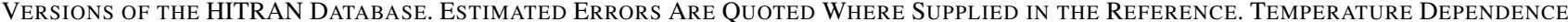

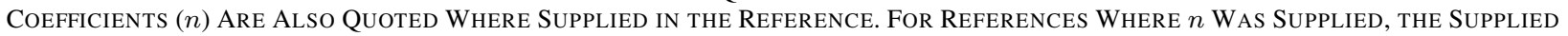

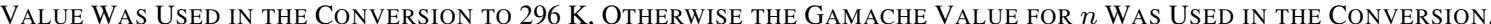

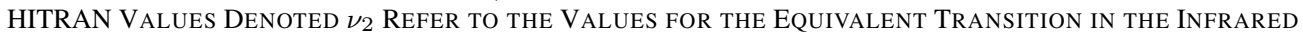

\begin{tabular}{|l|c|c|c|c|}
\hline $\mathbf{2 2 . 2 4} \mathbf{~ G H z}$ & \multicolumn{5}{|l|}{} \\
\hline Reference & $\begin{array}{l}\gamma\left[\mathbf{c m}^{-\mathbf{1}} \mathbf{a t m}^{-\mathbf{1}}\right] \\
\text { at } \mathbf{2 9 6 ~ K}\end{array}$ & Quoted error on $\boldsymbol{\gamma}$ & $\begin{array}{l}\text { Difference } \\
\text { from retrieved }\end{array}$ & $\mathbf{n}$ \\
\hline Becker \& Autler (1946) & 0.0918 & $12 \%$ & $+2 \%$ & - \\
\hline Liebe \& Dillon (1969) & 0.0959 & $2 \%$ & $+6 \%$ & 0.69 \\
\hline Mrowonski (1970) & 0.0942 & $3 \%$ & $+5 \%$ & - \\
\hline HITRAN 2000 + updates & 0.0906 & - & $+0.6 \%$ & 0.64 \\
\hline HITRAN 2004 & 0.0942 & - & $+5 \%$ & 0.64 \\
\hline HITRAN 2004 + updates $\left(v_{2}\right)$ & 0.0909 & - & $+1 \%$ & 0.64 \\
\hline HITRAN 2004 + updates & 0.0942 & - & $+5 \%$ & 0.64 \\
\hline Cazzoli et al. (2007) & 0.0878 & $4 \%$ & $-2 \%$ & - \\
\hline Gamache (this paper) & 0.0913 & $3 \%$ & $+1 \%$ & 0.755 \\
\hline Retrieved value from this work & 0.0900 & $1 \%$ & - & - \\
\hline
\end{tabular}

accuracy and are expected to be very similar to the microwave widths. For the 22-GHz line, the Rosenkranz microwave absorption model [29], [30] uses the value from [23] while the HITRAN 2000 plus updates value [25] was the one endorsed by Liljegren et al. [31]. For the 183-GHz line, the most recent version of the Rosenkranz microwave absorption model [30] uses the value from [23]. It can be seen that the differences between the measurements are sometimes larger than the quoted uncertainties.

A previous attempt to determine the air-broadened halfwidth of the 22-GHz linewidth using radiometer and radiosonde measurements was made by [41]. This group used a data set corresponding to 21 National Weather Service (NWS) radiosonde profiles in conjunction with a parameterized model for watervapor absorption to derive scaling factors for the $22-\mathrm{GHz}$ line strength, the linewidth, and the water-vapor continuum. Their result was that the best fit was obtained by scaling the width from [23] by 1.07. This value is not shown in Fig. 2/Table I (the work presented in this paper uses far more data, radiosondes that are believed to be of better quality than those used by the NWS, and a different water-vapor continuum).

The air-broadened half-width of the $183-\mathrm{GHz}$ line was retrieved by [42] using data from the Microwave Limb Sounder (MLS) on the Upper Atmosphere Research Satellite. The value from [42] was around 5\% higher than the value included in the most recent update to the HITRAN 2004 database [27], putting it at the higher end of the laboratory measurements and calculations shown in Fig. 2. The authors of the MLS work acknowledged that for limb measurements, a retrieval of the half-width is strongly affected by the pointing accuracy of the instrument, which might explain the discrepancy between their value and the other recent values shown in Fig. 2. 
TABLE II

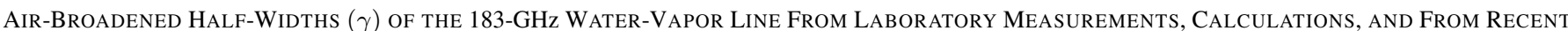
VERSIONS OF THE HITRAN DATABASE. ESTIMATED ERRORS ARE QUOTED WHERE SUPPLIED IN THE REFERENCE. TEMPERATURE DEPENDENCE

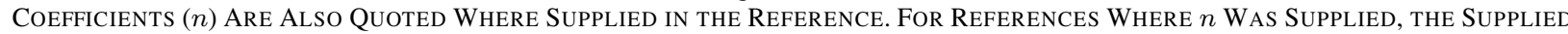
VAlue WAS USED IN THE CONVERSION TO $296 \mathrm{~K}$, OTHERWISE THE GAMACHE VALUE FOR $n$ WAS USED IN THE CONVERSION. HITRAN VALUES DENOTED $\nu_{2}$ REFER TO THE VALUES FOR THE EQUIVALENT TRANSITION IN THE INFRARED

\begin{tabular}{|c|c|c|c|c|}
\hline \multicolumn{5}{|l|}{$183.31 \mathrm{GHz}$} \\
\hline Reference & $\begin{array}{l}\gamma\left[\mathrm{cm}^{-1} \mathrm{~atm}^{-1}\right] \\
\text { at } 296 \mathrm{~K}\end{array}$ & Quoted error on $\gamma$ & $\begin{array}{l}\text { Difference } \\
\text { from retrieved }\end{array}$ & $\mathbf{n}$ \\
\hline Rusk (1965) & 0.0906 & $1 \%$ & $-9 \%$ & - \\
\hline Frenkel \& Woods (1966) & 0.1034 & $5 \%$ & $+4 \%$ & - \\
\hline Hemmi \& Straiton (1969) & 0.0843 & - & $-15 \%$ & - \\
\hline Ryadov \& Furashov(1975) & 0.0992 & $6 \%$ & $0 \%$ & - \\
\hline Bauer et al (1985) & 0.114 & $2 \%$ & $+15 \%$ & - \\
\hline Bauer et al (1989) & 0.0958 & $2 \%$ & $-3 \%$ & - \\
\hline Goyette \& de Lucia (1990) & 0.1027 & $1 \%$ & $+4 \%$ & - \\
\hline HITRAN $2000+$ updates & 0.0959 & - & $-3 \%$ & 0.64 \\
\hline Tretyakov et al (2003) & 0.0969 & $1 \%$ & $-2 \%$ & - \\
\hline HITRAN 2004 & 0.0984 & - & $-0.8 \%$ & 0.77 \\
\hline Golubniatnikov et al (2005) & 0.0993 & $1 \%$ & $+0.1 \%$ & - \\
\hline HITRAN $2004+$ updates $\left(v_{2}\right)$ & 0.0989 & - & $-0.3 \%$ & 0.77 \\
\hline HITRAN $2004+$ updates & 0.1014 & - & $+2 \%$ & 0.77 \\
\hline Gamache (this paper) & 0.0997 & $3 \%$ & $+0.5 \%$ & 0.769 \\
\hline Retrieved value from this work & 0.0992 & $2 \%$ & - & - \\
\hline
\end{tabular}

The line half-width is a function of temperature and pressure

$$
\gamma_{\text {air }}(P, T)=\gamma_{0, \text { air }}\left(\frac{P}{P_{0}}\right)\left(\frac{T_{0}}{T}\right)^{n}
$$

where $n$ is the temperature dependence of the width. For this paper, the value for the temperature dependence is important since the atmosphere viewed by the radiometer radiates at a lower temperature than the reference temperature of $296 \mathrm{~K}$. Different published values of the temperature dependence of the widths are also shown in Tables I and II.

\section{RADiOMETER MEAsurements}

\section{A. 22 GHz: The MWRP at the SGP}

The ARM program operated a 12-channel microwave radiometer profiler (MWRP) [1] from February 2000 to March 2002 at the SGP site near Lamont, OK. The MWRP was built by Radiometrics http://www.radiometrics.com). It has five channels in the region of the 22-GHz water-vapor line (22.235, $23.035,23.835,26.235$, and $30.0 \mathrm{GHz}$ ) as well as a further seven channels in the region of the $60-\mathrm{GHz}$ oxygen band. The five channels in the $22-\mathrm{GHz}$ region are double sideband, with bandwidths of $150 \mathrm{MHz}$ on either side of an 80-MHz gap centered on the quoted frequencies. The $30-\mathrm{GHz}$ channel showed anomalous behavior during the time period of interest for this paper when compared with another well-validated microwave radiometer at the SGP site (details of the comparisons between the two radiometers can be found in the MWRP handbook, available on the ARM website http://www.arm.gov). For this reason, it was decided that the $30-\mathrm{GHz}$ channel would be excluded from the analysis presented here. The positions of the MWRP channels are shown in Fig. 1, which shows modeled brightness temperature spectra for both downwelling radiation (as seen from the ground) and upwelling radiation (as seen from space) using differing total column water-vapor amounts representative of the conditions at the two measurement sites used in this paper. The MWRP instrument is a double sideband radiometer with a bandwidth of $200 \mathrm{MHz}$. The radiometric accuracy, according to the manufacturer, is $0.5 \mathrm{~K}$ for all channels.

\section{B. $183 \mathrm{GHz}$ : The GVR at the NSA}

The measurements used in this paper for the study of the 183-GHz line are from the G-band Vapor Radiometer (GVR), a ground-based instrument deployed at the ARM site at the NSA site near Barrow, AK. The GVR was developed and built by Prosensing, Inc. http://www.prosensing.com) [4], [43]. The instrument measures brightness temperatures from four double sideband channels centered at $\pm 1, \pm 3, \pm 7$, and $\pm 14 \mathrm{GHz}$ from the center of the 183.31-GHz water-vapor line. The positions of these channels are shown in Fig. 1. Bandwidths for the four channels are $0.4,1.0,1.4$, and $2.0 \mathrm{GHz}$. Prosensing expects better than $1 \mathrm{~K}$ calibration accuracy.

Conditions at the NSA site are typically extremely cold and dry. Conditions where the total column PWV is low are useful for studies of the spectroscopy of the $183-\mathrm{GHz}$ water-vapor line because the line remains unsaturated under these conditions. For the 183-GHz line, conditions of PWV less than around $2 \mathrm{~mm}$, often observed at the NSA site in winter, enable the observation of frequencies close to the line center without these frequencies becoming opaque.

\section{MOdel/MeAsurement COMPARISONS}

The methodology employed in the comparisons was to run MonoRTM using profiles of temperature and relative humidity from radiosondes launched at the instrument sites in order to simulate the brightness temperatures observed by the radiometers. Since radiosondes do not measure CLW amount, the comparisons were limited to conditions free of liquid clouds. Methods used to screen for clouds at the two sites are discussed in the sections that follow. Profiles of trace gases other than water vapor were represented using climatological profiles [44]. 

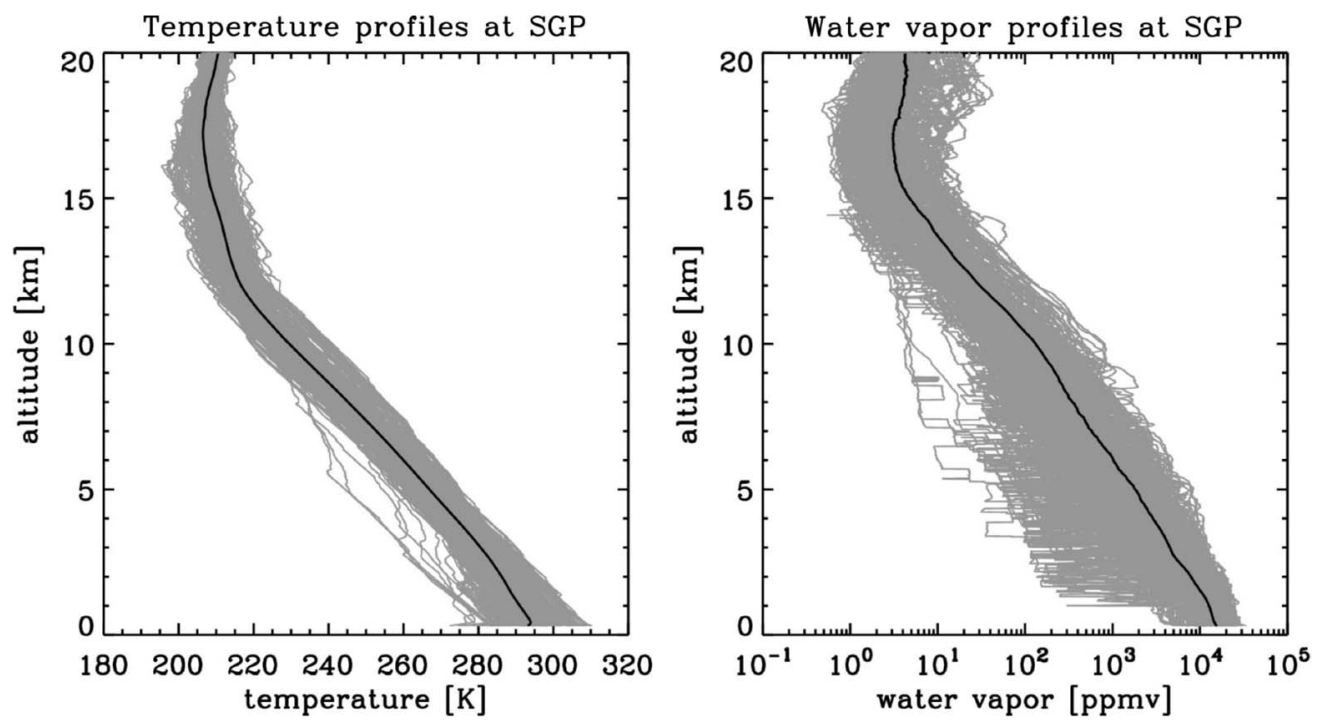

Fig. 3. Temperature and water-vapor profiles from radiosondes launched at the SGP site for the cases used in this paper. Gray lines show individual profiles, while the black line represents the mean profile for the data set in each case. Altitude here is the altitude above mean sea level. The SGP site is located $315 \mathrm{~m}$ above mean sea level.

It is assumed here that the radiosonde profile provides a reasonable estimate of the water-vapor profile. The assumption made in this paper is that any biases present in the sonde profile can be corrected for by scaling the profile. This assumption has proved useful in the context of the ARM Program [11]. For the 22-GHz line, the brightness temperature at the surface is linearly related to the PWV, and the precise vertical variations in water vapor are largely unimportant. For the $183-\mathrm{GHz}$ line, this linear relationship between total column water vapor and measured brightness temperature no longer necessarily holds, particularly for channels close to the line center. This issue is discussed further in Section IV-B. In any case, while the radiosonde profiles may not constitute "truth," they offer the best information available for input to the radiative transfer model in the comparisons presented here.

\section{A. Direct Comparisons With Radiosondes at $22 \mathrm{GHz}$}

The time period used for comparisons of MonoRTM with the MWRP at the SGP site was from February to August 2000. During this period, Vaisala RS-80 radiosondes were launched four times per day from the SGP site. The MWRP takes brightness temperature measurements at intervals of the order of $30 \mathrm{~s}$. For the comparisons with MonoRTM, the MWRP brightness temperatures were averaged from $5 \mathrm{~min}$ before to $30 \mathrm{~min}$ after the sonde launch, in order to take account of varying atmospheric conditions in the time taken for the sonde to reach its upper measurement altitudes. The profiles were screened for liquid cloud by examining the standard deviation of the $30-\mathrm{GHz}$ channel brightness temperatures over the time window used for averaging the MWRP data. In this time period, 204 profiles were deemed to be cloud free. Fig. 3 shows the radiosonde profiles of temperature and water-vapor mixing ratio (converted from relative humidity) used in the comparison, while Fig. 4 (left) shows the measured MWRP brightness temperatures as a function of PWV (calculated from the radiosonde profiles).
Fig. 5 shows the sensitivity of modeled brightness temperatures in the region of the $22-\mathrm{GHz}$ line to changes in the linewidth, PWV, and the foreign-broadened water-vapor continuum. For any given set of atmospheric conditions, there is a frequency point on either side of the line center for which the dependence of the modeled brightness temperature on the linewidth is at a minimum. The position of this "pivot point" lies close to the frequency one effective half-width from the line center. In this case, the effective width is the air-broadened half-width of the line at a representative temperature, weighted by the mean pressure for water vapor. The value is dependent on the mean water-vapor-weighted pressure, and is effectively $2.3 \mathrm{GHz}$ from the line center at the SGP site for this set of cases. Note that none of the MWRP channels coincide exactly with this "pivot point," but that the channel at $23.835 \mathrm{GHz}$ is least sensitive to uncertainties in the value of the linewidth.

MonoRTM calculations were performed at 25-MHz intervals over the bandpass function for each of the relevant MWRP channels. The resulting radiances were averaged, and the result converted to brightness temperature. An error in the half-width would be expected to result in a frequency-dependent slope in the residuals. The "raw" residuals (measurement minus model) contain a large degree of scatter, an additional slope (not frequency dependent) due to a general dry bias in the RS-80 sonde profiles and channel-dependent offsets due to instrument calibration uncertainty and/or errors in the model that do not depend on PWV (such as errors in the modeling of the oxygen absorption). Channel-dependent offsets were determined by noting the intercept of a fitted regression line with the brightness temperature at which the modeled brightness temperature is independent of the half-width for each channel. In general, the fitted offsets are within the estimated calibration uncertainty of $0.5 \mathrm{~K}$ quoted for the instrument. The offset for the $26.235-\mathrm{GHz}$ channel is slightly larger, at $0.7 \mathrm{~K}$. The dry bias associated with RS-80 has previously been recognized [11]. For the MWRP channels, this dry bias results in a positive slope in 

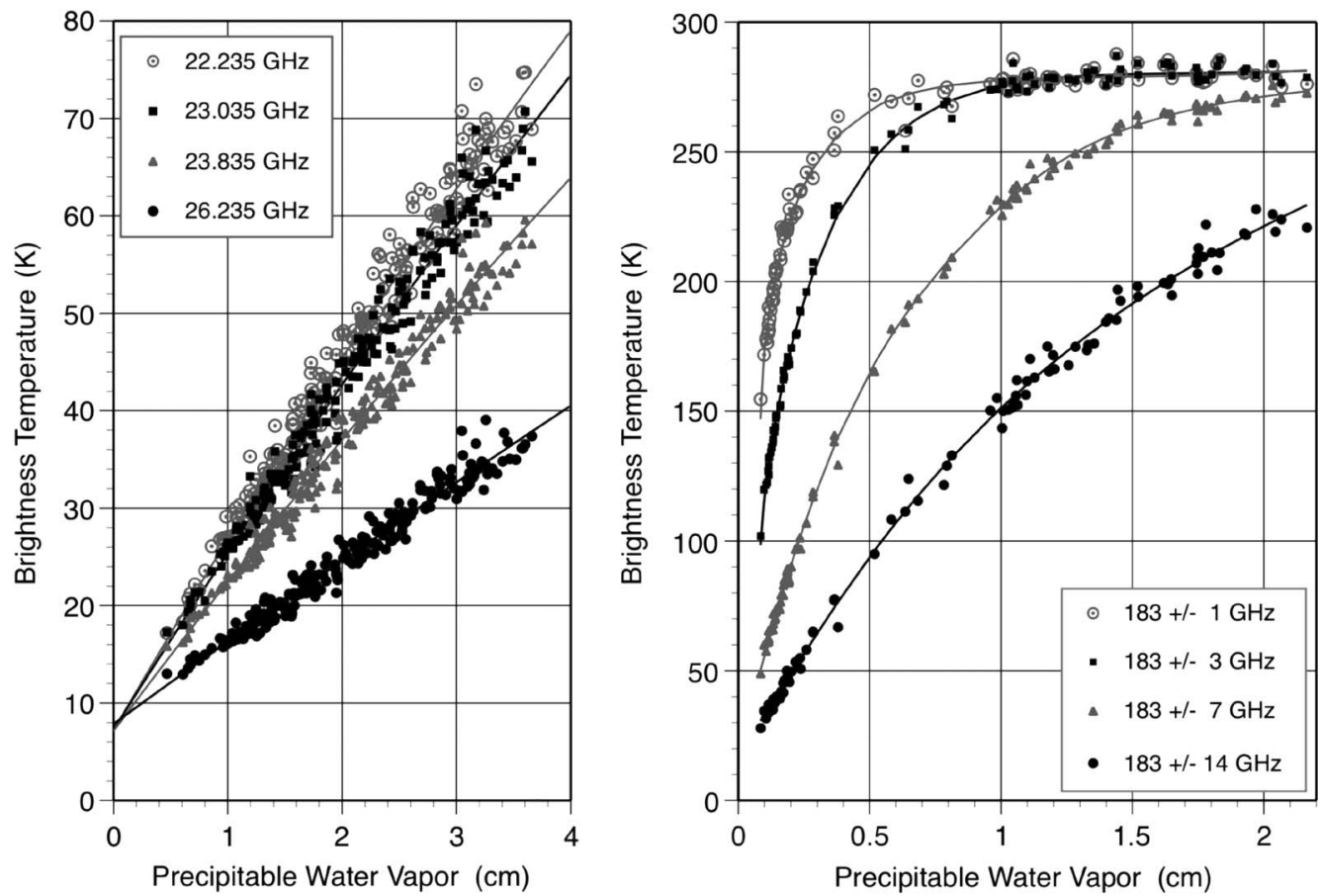

Fig. 4. (Left) MWRP measured brightness temperatures plotted against radiosonde PWV values for the cloud-free cases used in this paper. (Right) GVR measured brightness temperatures plotted against radiosonde PWV values for the cloud-free cases used in this paper.

the residuals. To correct for this effect, a slope was fitted to the residuals of the 23.835-GHz channel (the channel least sensitive to the half-width), and this same slope $(0.06 \mathrm{~K} / \mathrm{K})$ was removed from all channels. Fig. 6 shows the residuals obtained using a width value of $0.0913 \mathrm{~cm}^{-1}$, after the removal of channeldependent offsets and a constant slope for all channels. The remaining scatter in the differences is mainly associated with uncertainties in the individual radiosonde profiles, while the remaining slopes are assumed to be associated with an error in the half-width. The fact that the remaining slopes in Fig. 6 are small is an indication that the width used in the initial model comparison is a good initial guess.

\section{B. Direct Comparisons With Radiosondes at $183 \mathrm{GHz}$}

The time period used for comparisons of MonoRTM with the GVR at the NSA site was January to October 2007. The radiosondes launched during this time period at the NSA site were Vaisala RS-92s. During routine operations at the NSA site, radiosondes are launched twice per day. However, the period for which GVR data has been analyzed includes a special campaign, the "Radiative Heating in Underexplored Bands Campaign," between February 22 and March 14, 2007. Sonde launches were more frequent during this campaign, giving a higher incidence of clear-sky radiosonde matches. Screening for liquid clouds was performed using data from a ceilometer at the NSA site. One hundred profiles were deemed to be cloud free. Fig. 7 shows profiles of temperature and water-vapor mixing ratio (converted from relative humidity) for the cloudfree radiosonde profiles. Fig. 4 (right) shows the measured brightness temperatures as a function of PWV (calculated from the radiosonde profiles), demonstrating the high sensitivity of the GVR at low PWV, the high brightness temperatures in the $183-\mathrm{GHz}$ region compared to the $22-\mathrm{GHz}$ region and the thresholds at which the response of each GVR channel starts to flatten with increasing PWV. It is apparent (see Figs. 3 and 7) that conditions at the NSA site are markedly different from those at the SGP. The persistent strong temperature inversion near the surface at the NSA site requires that great care be taken in providing a good lower atmospheric profile to the model. Temperature information from a measurement tower was added to the bottom of the radiosonde profiles to construct the profiles used as input to MonoRTM for the $183-\mathrm{GHz}$ comparisons. Ground-based measurements at the NSA site are somewhat sensitive to stratospheric conditions due to the dry conditions (and to some extent, the lower tropopause height). Fig. 8 shows the stratospheric contribution to the observed brightness temperature at the ground for a range of column water-vapor values. The model was run first using a complete atmospheric profile, then again with the stratospheric humidity set to zero (but with the amounts of all molecules other than water vapor the same). The difference in modeled brightness temperature between these runs is shown in Fig. 8. It has been assumed here that relative to the troposphere, the stratosphere varies little and so the radiance contribution from the stratosphere is reasonably constant. Note that the stratospheric component of the total PWV is extremely small (only $5.0 \mathrm{e}-4 \mathrm{~cm}$ for the atmosphere used to generate Fig. 8). However, the stratospheric contribution can have a nonnegligible impact on instrument channels close to the $183-\mathrm{GHz}$ line center for low tropospheric water-vapor amounts, and so it is desirable to include a reasonable representation of the stratosphere in the model. The relative humidities measured by the radiosondes tend not to go below a minimum value of around $1 \%$ and are, therefore, unable to capture the extreme dryness of the stratosphere. Conversions of NSA stratospheric radiosonde relative humidities to volume mixing ratios (VMRs) 

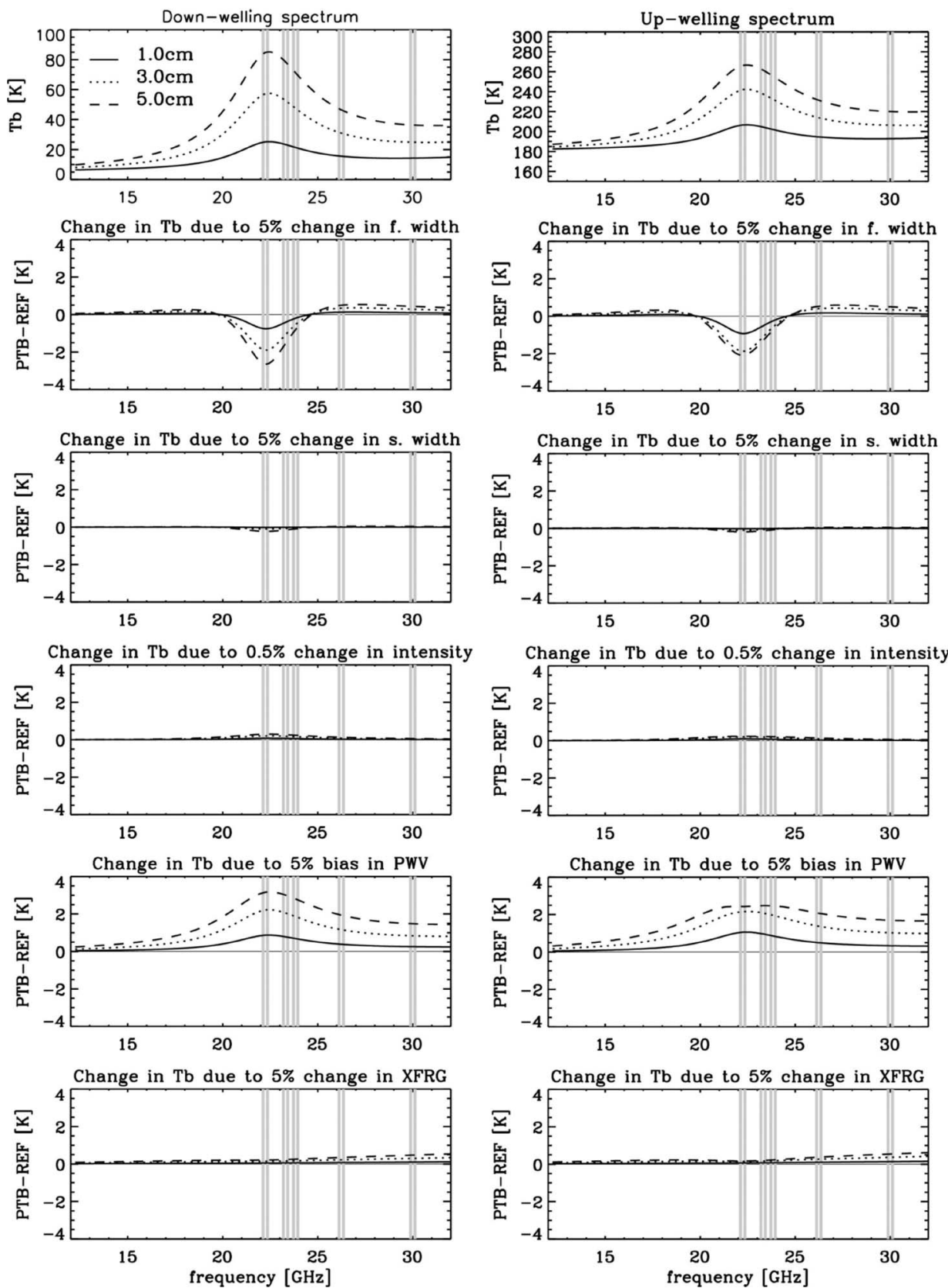

Fig. 5. Sensitivity of modeled brightness temperature in the region of the 22-GHz line to changes in linewidth, PWV and foreign-broadened water-vapor continuum. The left column shows the impact of changes in these parameters to the downwelling spectrum, while the right column shows the impact of changes to the upwelling spectrum. Different line styles denote different column water-vapor amounts. Values chosen for the total column water-vapor reflect the range of PWV values observed at the SGP site over the time period of interest. Shaded regions denote the positions of the MWRP channels in this range.

result in values of the order of $50 \mathrm{ppmv}$, which are clearly unrealistic. In order to avoid such large stratospheric watervapor amounts, any radiosonde VMRs above $9 \mathrm{~km}$ deemed to be unreasonably large were set to climatological values, leading to the convergence of profiles in Fig. 7. Temperature profiles above the uppermost sonde altitude were set to scaled climatological values. Climatological profiles were used for ozone.

The GVR takes brightness temperature measurements every 9 to $10 \mathrm{~s}$. As with the 22-GHz comparisons, the GVR brightness temperatures were averaged over a $35 \mathrm{~min}$ window around the sonde launch time in order to account for the time that the radiosonde takes to reach its limit. MonoRTM calculations were performed at $100-\mathrm{MHz}$ intervals over the bandpass func- tion for each of the GVR channels. The bandpass functions were assumed to be square, with widths as specified by the manufacturer. The resulting radiances were averaged for each channel and then converted to brightness temperatures using a frequency of $183.31 \mathrm{GHz}$ for the conversion. Fig. 9 shows comparisons between modeled (MonoRTM) and measured (GVR) brightness temperatures for the cloud-free radiosonde launches, for two different "initial guess" values for the halfwidth, alongside plots showing the sensitivity of the modeled brightness temperature to a $5 \%$ change in the half-width. The initial guess values are based on $0.0989 \mathrm{~cm}^{-1} / \mathrm{atm}$, which is the latest HITRAN value for the equivalent transition in the $\nu_{2}$ region in the infrared (see Table II). Much of the scatter in the 

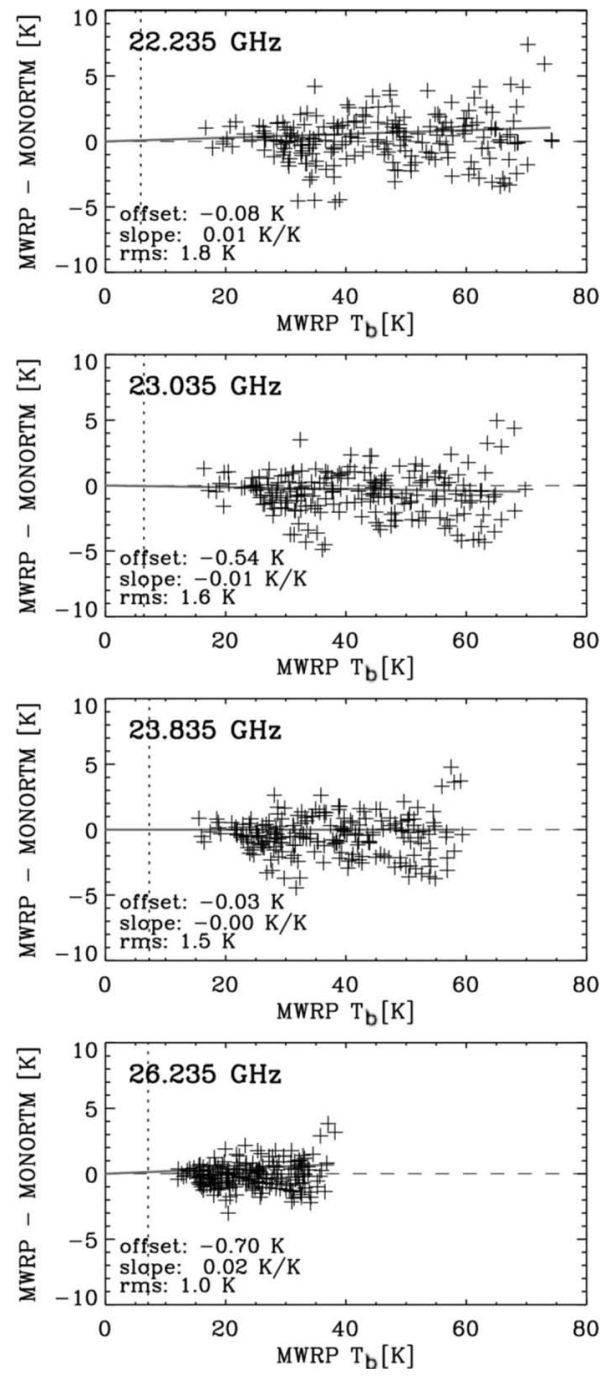

Fig. 6. MWRP brightness temperature comparisons after the removal of a constant slope $(0.06 \mathrm{~K} / \mathrm{K})$ from all channels and after the application of a channel-dependent offset, using a half-width of $0.0913 \mathrm{~cm}^{-1} / \mathrm{atm}$ and a temperature dependence of 0.76 . This width value is the one used in the initial guess of the width retrieval. The quoted rms values for each channel indicate the rms around the regression line. The vertical dotted lines indicate the lower bound at which the modeled brightness temperature becomes insensitive to the width used, and the quoted offset values represent the value of the raw model $/$ measurement differences at the vertical dotted line.

differences can be attributed to uncertainties in the radiosonde profiles. It can be seen that the value of $0.0989 \mathrm{~cm}^{-1} /$ atm gives better model/measurement agreement for the \pm 1 - and $\pm 7-\mathrm{GHz}$ channels, and so can be assumed to be a reasonable initial guess. The $183 \pm 14-\mathrm{GHz}$ residuals are not consistent with those from the other channels. This indicates a problem either with the calibration or with the modeling of this channel. Problems with the modeling of the channel could include both the spectroscopic parameters used in the model and the assumptions made about the bandpass function. It seems unlikely that such large residuals would be due to calibration. The GVR is calibrated using an ambient $(290 \mathrm{~K})$ and a hot (340 K) load. If the residuals were due to a calibration issue, it would be expected that the disagreement between model and measurement would be worst at low brightness temperatures, which is not the case here. Also, the magnitude of any calibration error should be similar for the \pm 7 - and $\pm 14-\mathrm{GHz}$ channels for a given temperature range. If the only problem with the model were an error in the $183-\mathrm{GHz}$ linewidth, then the residuals for the \pm 14 channel would be similar in shape and sign to the \pm 7 residuals. A bias in the radiosonde PWV would also produce residuals similar in shape and sign in both the \pm 14 - and $\pm 7-\mathrm{GHz}$ channels. However, the modeled brightness temperatures at the $183 \pm 14-\mathrm{GHz}$ channel are more sensitive to uncertainties in the spectroscopic parameters of strong water-vapor lines at higher frequencies. It is likely that the residuals for the $183 \pm 14$ channel could be improved by updating the widths of some of these strong high-frequency lines. Such updates will require data that is not available here and so for this paper, it is necessary to treat the $183 \pm 14-\mathrm{GHz}$ channel with caution. Modeled brightness temperatures at $183 \pm 14 \mathrm{GHz}$ are also more sensitive to the bandpass function, due to the larger width of this channel. Previous attempts to explore the use of the $183 \pm 14-\mathrm{GHz}$ channel for liquid water retrievals [4] led to the conclusion that the results obtained were markedly different from those obtained using the $22-30-\mathrm{GHz}$ region. The work presented in this paper indicates that further validation of spectroscopic parameters for higher frequency lines and further investigation of the instrument bandpass would be advisable before attempting to use the $183 \pm 14-\mathrm{GHz}$ channel for liquid water retrievals.

It can be seen from Fig. 9 that the response of the modeled brightness temperatures to a change in the width is not linear. In the limit of both low and high PWV (low and high measured brightness temperature), the modeled brightness temperatures become insensitive to the width. For the $183 \pm 1$ - and $\pm 3-\mathrm{GHz}$ channels, the data reaches this insensitive region at the high end of the data set. There is an obvious offset to the clusters of highend data points above, for example, $260 \mathrm{~K}$ (see also Fig. 4). These high-end clusters were used to determine an offset for each of these channels. The $183 \pm 7-\mathrm{GHz}$ residuals provide no overwhelming evidence for the need for an offset, while the $\pm 14-\mathrm{GHz}$ residuals shows a strong dependence on the PWV. It was decided not to use the $\pm 14-\mathrm{GHz}$ channel in the analysis, but the results are shown for information.

Fig. 10 shows the sensitivity of the modeled monochromatic brightness temperature spectrum in the region of the $183-\mathrm{GHz}$ line to different forward model parameters of interest. The effect of the different parameters on the brightness temperature varies both with frequency and with PWV. A 5\% error in the air-broadened half-width of the line would lead to a large model/measurement difference near the line center at low PWV and a zero difference at higher PWV above $1 \mathrm{~cm}$. Note that the "pivot point" of the $183-\mathrm{GHz}$ line, the frequency at which the modeled radiance/brightness temperature is insensitive to the width used, is situated approximately $2 \mathrm{GHz}$ from the line center for NSA conditions. The GVR channel that is least sensitive to the width is the $183 \pm 3-\mathrm{GHz}$ channel. A consistent bias in the radiosonde PWV would result in a slope in the residuals in both the $183 \pm 7$ - and $\pm 14-\mathrm{GHz}$ GVR channels. Since this is not observed, it can be assumed that if there is any bias in the total column water vapor from the RS92 sondes, it must be considerably less than $5 \%$. A $5 \%$ error in the foreignbroadened water vapor continuum would also result in a slope in the residuals for two channels farthest from the line center. 

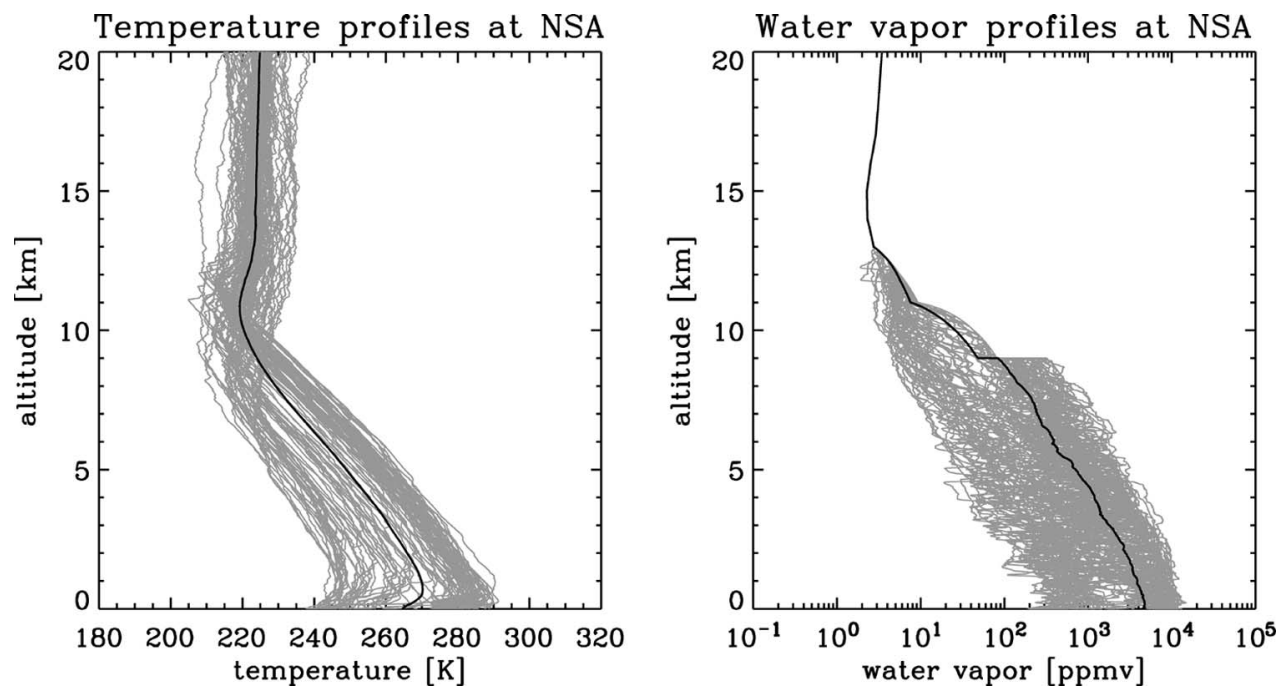

Fig. 7. Temperature and water-vapor profiles from radiosondes launched at the NSA site for the cases used in this paper. Gray lines show individual profiles, while the black line represents the mean profile for the data set in each case. Relative humidities from the radiosondes were converted to VMR. Above $9 \mathrm{~km}$, any radiosonde VMRs deemed to be unreasonably large were set to climatological values.

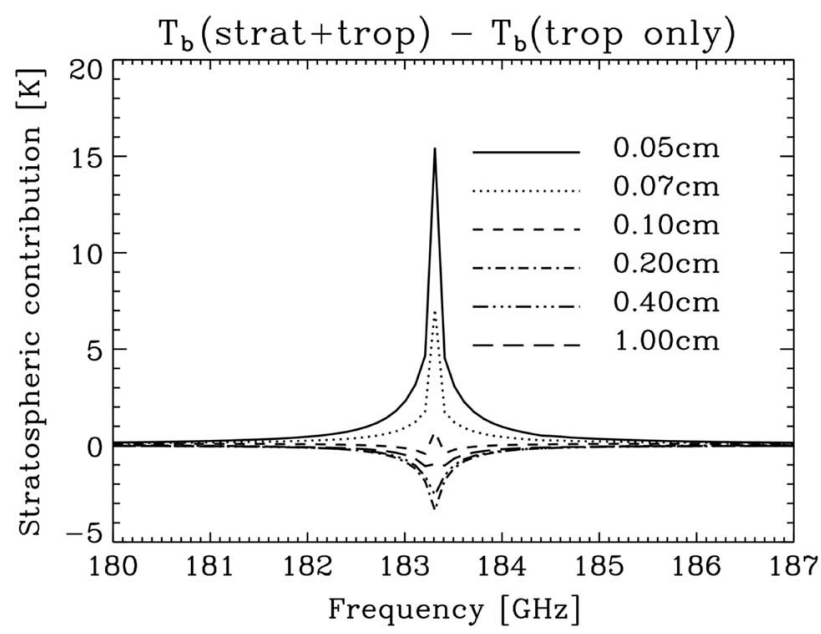

Fig. 8. Contribution of the stratospheric radiance contribution to the brightness temperature observed at the ground for different tropospheric water-vapor column amounts.

Based on previous work with the 22-GHz region, errors in the foreign-broadened water-vapor continuum can be assumed to be small —of the order of 3\% [45]. There are ozone lines present at $164.95,165.78,184.37,184.67$, and $195.43 \mathrm{GHz}(-18.36$, $-17.53,+1.06,+1.36$, and $+12.12 \mathrm{GHz}$ from the line center). The $183 \pm 1-\mathrm{GHz}$ channel is the only one affected by ozone.

\section{Best Estimate of LinewidTh AND ASSOCIATED UNCERTAINTY}

The measurements and the model can be used to determine the values of the air-broadened half-widths for the 22- and 183-GHz lines that give the best agreement. It is evident (see Figs. 5 and 10) that the linewidth is not the only parameter affecting the measurement. Given the scatter in the residuals (Figs. 6 and 9), it could be potentially difficult to distinguish between model/measurement differences due to uncertainties in the sonde PWV, the sonde profile, the linewidth, and possible uncertainties in instrument calibration. An approach has been adopted here that aims to decouple the uncertainties due to these factors.

The retrievals described in this section were performed using an optimal estimation technique [46]. The approach adopted here can be viewed as an iterative process. The same approach was employed in both the 22- and $183-\mathrm{GHz}$ regions. The steps employed to obtain a best estimate of the air-broadened halfwidths and associated estimates of uncertainty are outlined below.

The first step was to use the direct (raw) residuals from the measurement/model comparisons to determine bias offsets for each channel of each instrument. The determination of these offsets has already been discussed in Section IV. The next step was to reduce the scatter in the residuals to a point where the signal from the width could be distinguished from the background scatter.

In order to decouple the uncertainty in the sonde PWV from the uncertainty in the widths of the lines, scaling factors for PWV were retrieved for each radiosonde profile using measurements from the instrument channel that was least sensitive to the width. For the MWRP, this was the channel at $23.835 \mathrm{GHz}$. The initial guess and a priori values for each scaling factor were set to 1.0, and the a priori uncertainty on the scaling factors was set to $20 \%$. The retrieved PWV scaling factors from this step were then applied to each profile, and all channels were used to retrieve an estimate of the width, using the Gamache values (see Table III, Fig. 2, and Section VI) as the first guess and the a priori value for the width and the corresponding Gamache temperature dependencies for each line. The a priori uncertainty on the width was taken to be $5 \%$. For the $22-\mathrm{GHz}$ channels, where the response of brightness temperature to PWV and to the width can be taken to be linear, this was taken to be the best estimate of the width.

For the GVR, the response of brightness temperature to PWV and to the width is not linear over the range of measured brightness temperatures (see Fig. 4), and therefore, further 

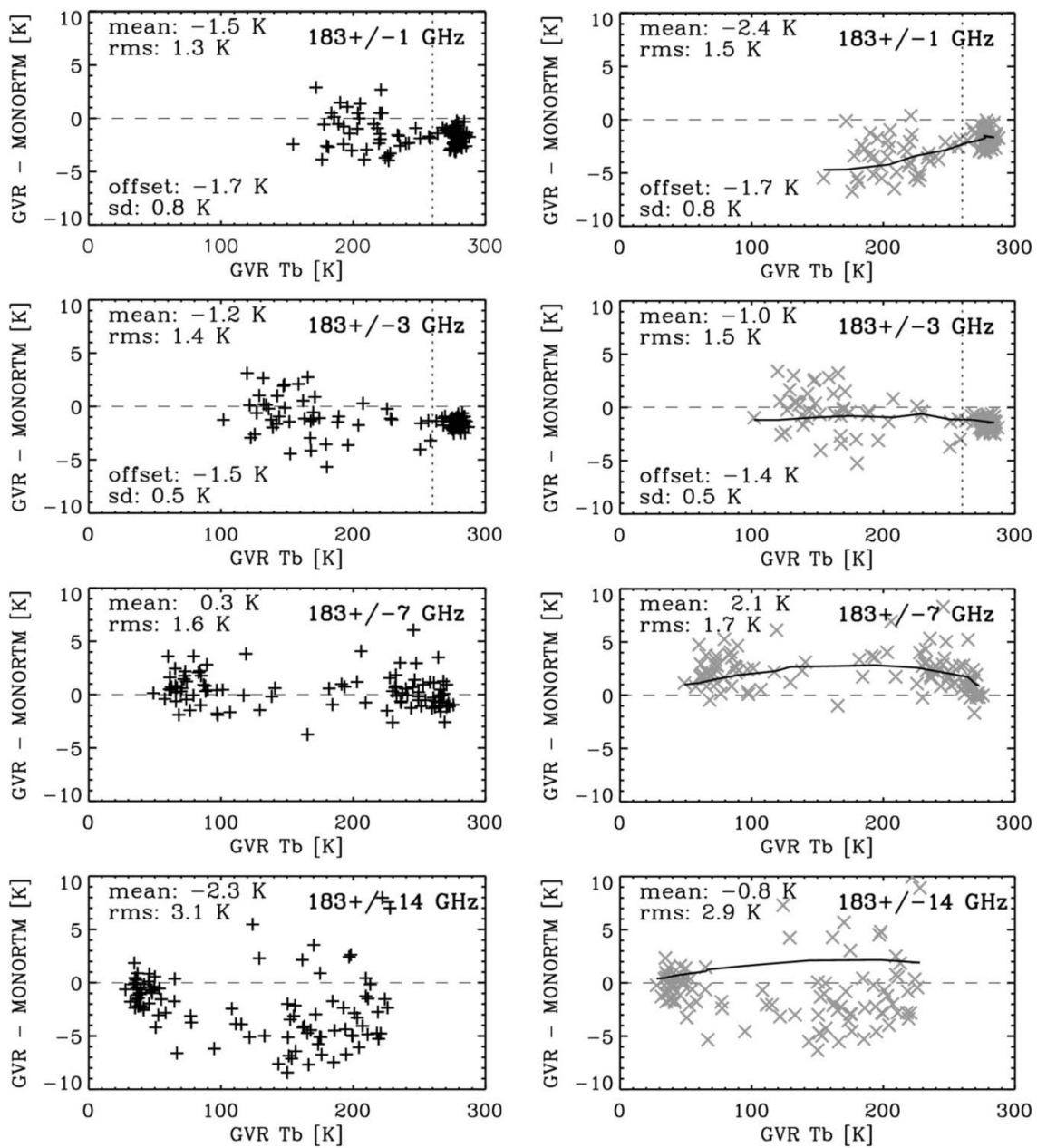

Fig. 9. (Left column) Direct GVR/MonoRTM brightness temperature comparisons (raw radiosonde profiles), using a width of $0.0989 \mathrm{~cm}^{-1} / \mathrm{atm}$ in MonoRTM with a temperature dependence of 0.77 . Quoted mean and rms model/measurement differences are shown for each channel. Vertical dotted lines shown in the $183 \pm 1$ - and $\pm 3-\mathrm{GHz}$ channel plots show the brightness temperature above which these channels were deemed to be saturated. Quoted offsets and standard deviations for these two channels denote are based on points to the right of the saturation lines. (Right column) Direct GVR/MonoRTM brightness temperature comparisons, using a width of $0.95 * 0.0989 \mathrm{~cm}^{-1} / \mathrm{atm}$. The solid lines on these plots show the change in modeled brightness temperature for a $5 \%$ decrease in the width of the $183-\mathrm{GHz}$ line.

iterations were necessary. For the first step, scaling factors for PWV were retrieved for each radiosonde profile using measurements from the $183 \pm 3-\mathrm{GHz}$ channel. The $183 \pm 3-\mathrm{GHz}$ channel is sensitive to the profile shape, so in this step it had to be assumed that the radiosonde profiles of temperature and relative humidity were good representations of the true profile shape. In addition, the $183 \pm 3-\mathrm{GHz}$ channel exhibits a nonlinear response to the total water column water vapor. An upper bound of $180 \mathrm{~K}$ was applied at this step in order to limit the extent of this nonlinearity. Scaling factors were not retrieved for profiles where the measured brightness temperature in the channel of interest was greater than this threshold. Again, the retrieved PWV scaling factors from this step were applied to each profile, and the $\pm 1-, 3-$, and 7-GHz channels were used to retrieve an estimate of the width. The updated width value was implemented, and an updated set of PWV scaling factors was retrieved using the $183 \pm 7-\mathrm{GHz}$ channel, with a brightness temperature threshold of $120 \mathrm{~K}$ (over this range, the response of brightness temperature to PWV is linear). Using the improved estimates of PWV from this step, a final retrieval of the width was performed using all channels.
It should be noted that the answers obtained here for the best estimate of the widths have some dependence on the temperature dependence of the width [(1)] used in the model. The width values from calculations are supplied to the model as values at $296 \mathrm{~K}$. At the SGP site, atmospheric temperatures are reasonably close to this value, and therefore, the effect of the value assumed for the temperature dependence of the width of the 22-GHz line does not have a significant effect on the results obtained here. At the NSA site, atmospheric temperatures for the cold dry conditions that provide the best information on the linewidth are significantly lower than $296 \mathrm{~K}$. Assuming a typical atmospheric temperature of $255 \mathrm{~K}$ (Fig. 7), using a temperature dependence of 0.64 instead of 0.769 (Table III) results in a $2 \%$ difference in the $183-\mathrm{GHz}$ width at $255 \mathrm{~K}$. However, based on work in the infrared region and on the calculations presented in Section VI, the value of 0.64 is not believed to be realistic. The uncertainty from the fitting of the temperature dependencies for the Gamache CRB calculations is only of the order of $1 \%$. The impact of this magnitude of uncertainty in the temperature dependence on the $183-\mathrm{GHz}$ width is negligible. 

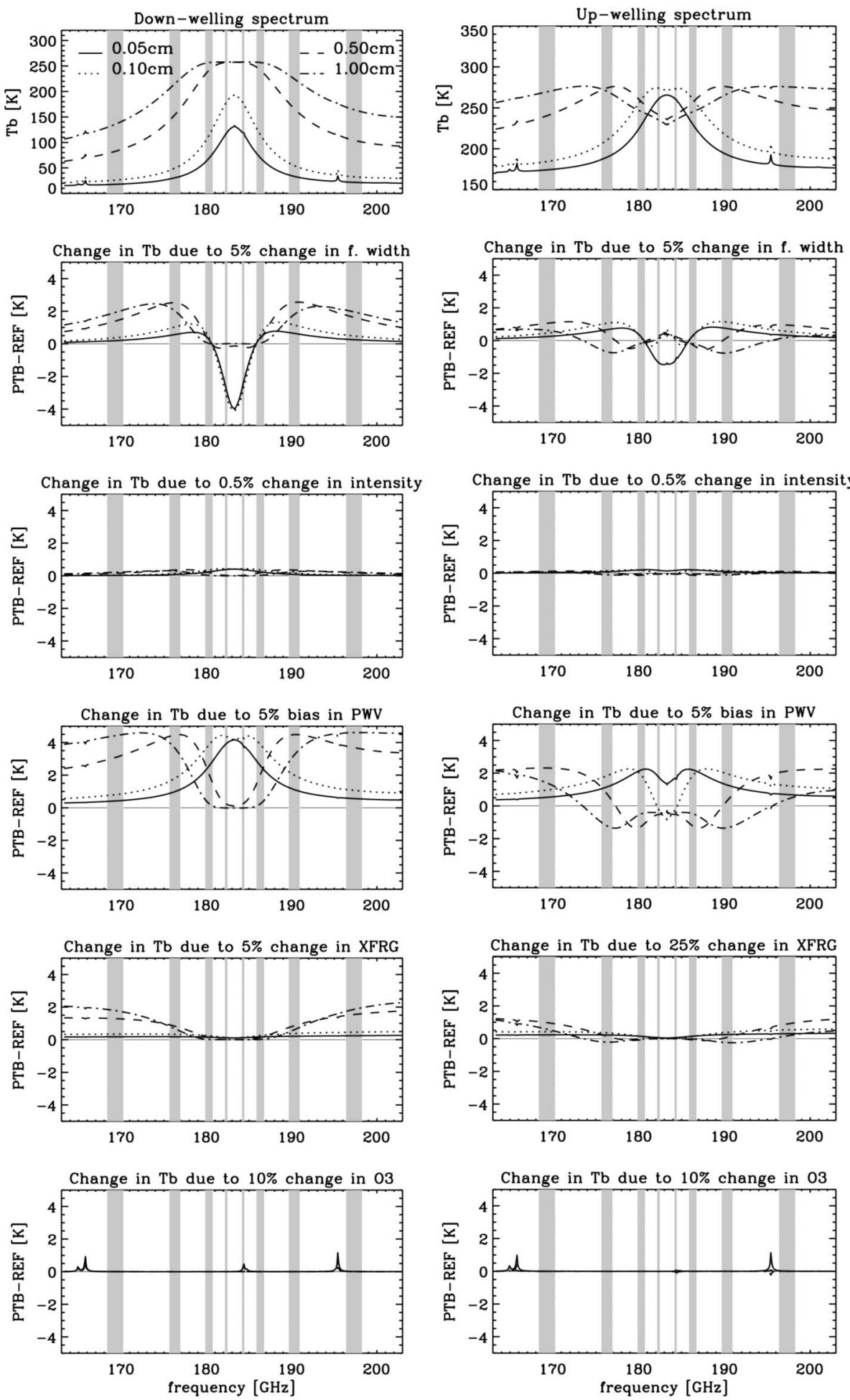

Fig. 10. Sensitivity of modeled brightness temperature in the region of the 183-GHz line to changes in linewidth, PWV, foreign-broadened water-vapor continuum, and ozone. The left column shows the impact of changes in these parameters to the downwelling spectrum, while the right column shows the impact of changes to the upwelling spectrum. Different line styles denote different column water-vapor amounts. Values chosen for the total column water vapor reflect the range of PWV values observed at the NSA site over the time period of interest. Shaded regions denote the positions of the GVR channels.

\section{A. Results at $22 \mathrm{GHz}$}

Fig. 11 shows model/measurement brightness temperature differences after the retrievals of PWV scaling factors and width. The final estimate of the width was $0.0900 \mathrm{~cm}^{-1} / \mathrm{atm}$. This value is shown as a dotted line in Fig. 2(a) in order to compare with other values from the literature. The retrieval error on the width due to random error obtained from the optimal estimation calculation is very small (less than $0.1 \%$ ). However, the model/measurement differences after the retrieval (Fig. 11, left) still show some small offsets and slopes, indicating some systematic error contribution. The total error bound, including systematic error contributions, on the retrieved width value 
TABLE III

Half-Width $(\gamma)$, Temperature Dependence of The Half-Width $(n)$, AND LINE SHIFT $(\delta)$ FOR THE 22- AND 183-GHz LINES AT $296 \mathrm{~K}$ With AIR AS THE BUFFER GAS FROM NEW CRB Calculations By R. R. Gamache

\begin{tabular}{|c|c|c|c|}
\hline Transition & $\gamma\left(\mathrm{cm}^{-1} \mathrm{~atm}^{-1}\right)$ & $n$ & $\delta\left(\mathrm{cm}^{-1} \mathrm{~atm}^{-1}\right)$ \\
\hline $\begin{array}{c}22.24 \mathrm{GHz} \\
6_{16} \leftarrow 523\end{array}$ & 0.0913 & 0.755 & -0.000882 \\
\hline $\begin{array}{c}183.31 \mathrm{GHz} \\
3_{13} \leftarrow 220\end{array}$ & 0.0997 & 0.769 & -0.00269 \\
\hline
\end{tabular}

was determined using the values of the offsets and slopes for each channel remaining in the residuals in Fig. 11 (left). The offsets and slopes were used to create an outer bound for a vector of systematic errors in brightness temperature space, which was propagated through to retrieval parameter space using the optimal estimation gain matrix. The total error using this method was found to be of the order of $1 \%$. A second more pessimistic estimate of the systematic error contribution was calculated by assuming a $1 \mathrm{~K}$ uncertainty in the temperature profile at all levels, a 3\% uncertainty in the foreign-broadened water-vapor continuum, a $0.5 \%$ uncertainty in the line intensity, a 5\% uncertainty in the self-broadened half-width, and a 1.5\% uncertainty in the PWV (uncertainties due to instrument calibration were accounted for in the determination of channel dependent offsets for this instrument). The estimated errors in brightness temperature space were propagated into retrieval parameter space using the optimal estimation gain matrix. The contributions of each of these error terms to the total are shown in Table IV. The estimated total error on the retrieved width value using this second method is $1.6 \%$. The larger of the two error estimates has been adopted.

\section{B. Results at $183 \mathrm{GHz}$}

Fig. 12 shows model/measurement brightness temperature comparisons after the retrievals of PWV scaling factors and width. The final estimate of the width was $0.0992 \mathrm{~cm}^{-1} / \mathrm{atm}$. This value is shown as a dotted line in Fig. 2(b) in order to compare with other values from the literature. Again, the retrieval error on the width due to random error obtained from the optimal estimation calculation is very small (of the order of $0.1 \%$ ). The nonlinear response of the $183-\mathrm{GHz}$ channels to PWV and width changes does not allow an error analysis of the first type described in Section V-A. The systematic error contribution was calculated using a number of assumptions. A $1 \mathrm{~K}$ uncertainty in the temperature profile at all levels, a $10 \%$ uncertainty in the column ozone amount, a $3 \%$ uncertainty in the foreign-broadened water-vapor continuum, a $0.5 \%$ uncertainty in the line intensity, a $1 \mathrm{~K}$ uncertainty in the instrument calibration, and a $1.5 \%$ uncertainty in the PWV were assumed. It was assumed that the uncertainty in the water-vapor profile is no larger than 5\% for any particular layer in the atmosphere. Simulations were performed where a $5 \%$ PWV perturbation was applied in wide atmospheric layers, in order to evaluate the effect of uncertainties in the water-vapor profile shape. The estimated errors in brightness temperature space were propagated into retrieval parameter space using the optimal estimation gain matrix. The contributions of each of these error terms to the total are shown in Table V. The estimated total error on the retrieved width value is $2.4 \%$.

\section{New Spectroscopic Parameters FROM CALCULATIONS}

The retrieved width values should be examined in the context of results of state-of the-art theoretical calculations. The calculations presented here are based on the complex implementation of the Robert-Bonamy (CRB) theory [47]. A description of the complex formalism has been given before [48], [49], here only the salient features are presented. The method is complex valued so that the half-width and line shift are obtained from a single calculation. The dynamics are developed to second order in time giving curved trajectories based on the isotropic part of the intermolecular potential [47], which has important consequences in the description of close intermolecular collisions (small impact parameters).

Within the CRB formalism the half-width $g$ and line shift $d$ of a rovibrational transition $f \leftarrow i$ are given by minus the imaginary part and the real part, respectively, of the diagonal elements of the complex relaxation matrix. In computational form the half-width and line shift are usually expressed in terms of the Liouville scattering matrix [50], [51]. The exact forms of the first- and second-order terms in the expansion of the scattering matrix are given in [48], [49], and [52].

The intermolecular potential employed in the calculations consists of the leading electrostatic components for the $\mathrm{H}_{2} \mathrm{O}-\mathrm{N}_{2}$ or $-\mathrm{O}_{2}$ system (the dipole and quadrupole moments of $\mathrm{H}_{2} \mathrm{O}$ with the quadrupole moment of $\mathrm{N}_{2}$ or $\mathrm{O}_{2}$ ), atom-atom interactions [53] and the isotropic induction and London dispersion interactions. The atom-atom terms are defined as the sum of pairwise Lennard-Jones 6-12 interactions [54] between atoms of the radiating and the perturbing molecules. The heteronuclear Lennard-Jones parameters for the atomic pairs are determined using the "combination rules" of [55]. The atomatom distance $r_{i j}$ is expressed in terms of the center of mass separation $R$ via the expansion in $1 / R$ [56]. Here, the formulation of [51] expanded to eighth order is used. For water vapor, the reduced matrix elements are evaluated using wavefunctions determined by diagonalizing the Watson Hamiltonian [57] in a symmetric top basis. The Watson constants of [58] were used for the (000) vibrational state. All molecular parameters for the $\mathrm{H}_{2} \mathrm{O}-\mathrm{N}_{2}$ or $\mathrm{H}_{2} \mathrm{O}-\mathrm{O}_{2}$ systems used in this paper are the best available values from the literature, no parameters are adjusted. The values used can be found in [59].

The calculations were made for the $22 \mathrm{GHz}\left(6_{16} \leftarrow 5_{23}\right)$ and the $183 \mathrm{GHz}\left(3_{1} \leftarrow 2_{2}\right)$ transitions of $\mathrm{H}_{2} \mathrm{O}$ broadened by $\mathrm{N}_{2}$ and by $\mathrm{O}_{2}$ at seven temperatures $(200,250,296,350$, 500,700 , and $1000 \mathrm{~K}$ ) by explicitly performing the averaging over the Maxwell-Boltzmann distribution of velocities. At each of the temperatures studied, the half-width and line shift for air as the buffer gas were obtained assuming binary collisions and Dalton's law

$$
\begin{aligned}
& \gamma_{\text {air }}=0.79 \gamma_{\mathrm{N}_{2}}+0.21 \gamma_{\mathrm{O}_{2}} \\
& \delta_{\text {air }}=0.79 \delta_{\mathrm{N}_{2}}+0.21 \delta_{\mathrm{O}_{2}} .
\end{aligned}
$$



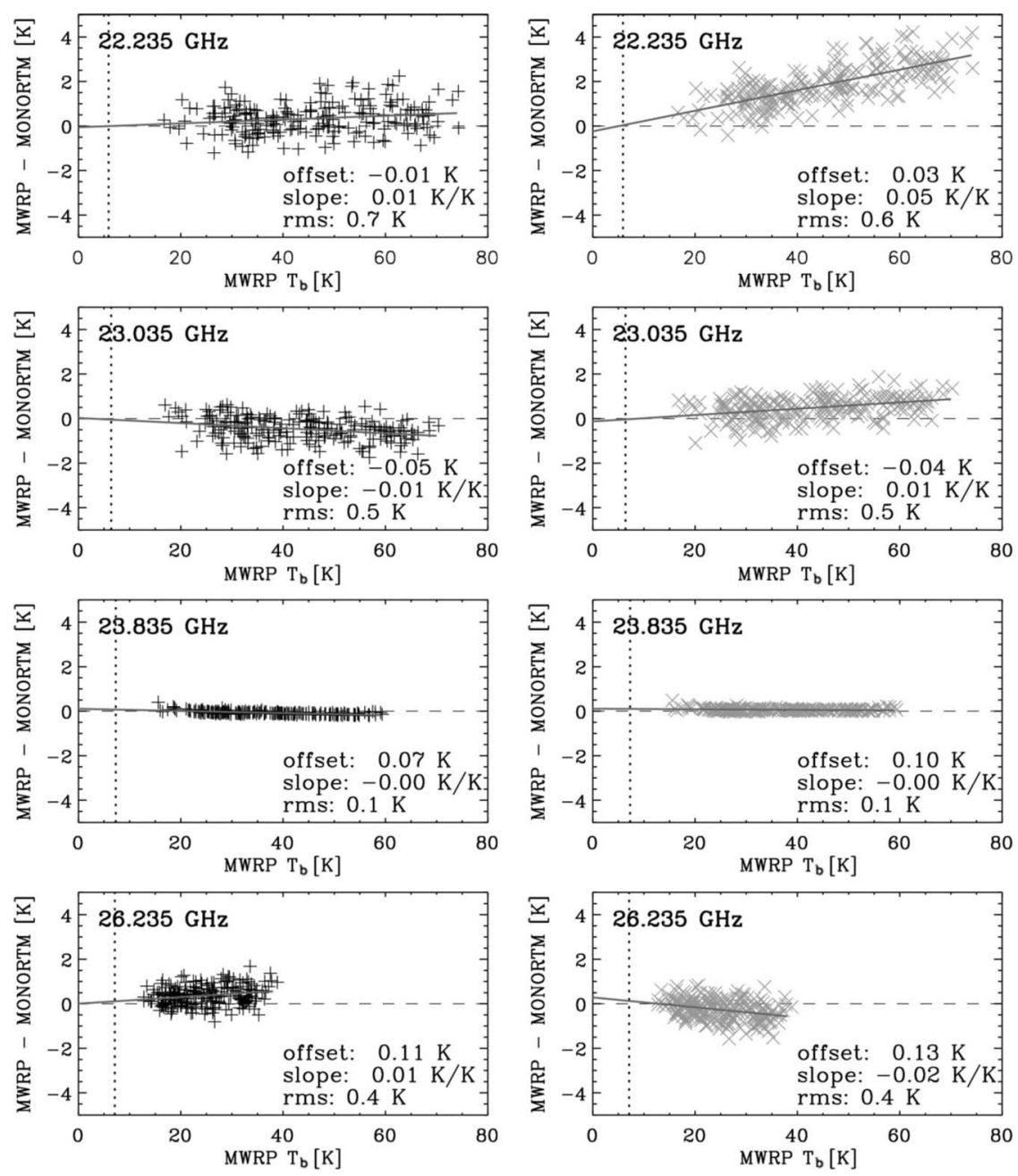

Fig. 11. Brightness temperature comparisons between MonoRTM and the MWRP after the determination of an offset for each channel and the retrieval of PWV from the $23.835-\mathrm{GHz}$ channel. The left column (black crosses) shows the results obtained from the retrieved width value of $0.0900 \mathrm{~cm}^{-1}$, while the right column (gray crosses) shows the results obtained by performing the same exercise using the Liebe width of $0.0959 \mathrm{~cm}^{-1}$ (note that the scale on the $y$-axis differs from that in Fig. 6).

TABLE IV

ERROR CONTRIBUTIONS FOR THE 22-GHz LINEWIDTH RETRIEVAL

\begin{tabular}{|l|c|}
\hline Error source & Contribution \\
\hline Random retrieval error & Less than $0.001 \%$ \\
\hline $1 \mathrm{~K}$ temperature uncertainty & Less than $0.1 \%$ \\
\hline $3 \%$ continuum uncertainty & $0.2 \%$ \\
\hline $1.5 \%$ PWV uncertainty & $1.5 \%$ \\
\hline $0.5 \%$ intensity uncertainty & $0.5 \%$ \\
\hline $5 \%$ self-broadened halfwidth uncertainty & $0.2 \%$ \\
\hline Total & $\mathbf{1 . 6} \%$ \\
\hline
\end{tabular}

The temperature dependence of the width $n$ [see (1)] was determined using the four points in the range $200 \mathrm{~K}-350 \mathrm{~K}$ where the reference temperature $T_{0}$ was taken as $296 \mathrm{~K}$. For both transitions studied the power law model gives an excellent fit to the data. The line parameters (air-broadened half-widths, temperature dependencies, and pressure shifts) are given in Table III. Sensitivity tests involving assumptions involved in the calculation of the potentials for these lines indicate uncertainties in the width values to be no greater than $3 \%$. The pressure shift does not have an appreciable impact on the modeling of the downwelling radiation at the ground, and therefore, the value used does not have an impact on the value for the air-broadened half-width obtained in this paper. However, the pressure shift is important for the accurate modeling of upwelling radiation at the top of the atmosphere and is particularly important for limb-viewing observations [42]. The values for the airbroadened half-widths presented in Table III agree with the values obtained using data from ground-based radiometers to within $1.4 \%$ for the $22-\mathrm{GHz}$ line and within $0.5 \%$ for the $183-\mathrm{GHz}$ line.

\section{CONCLUSION}

Air-broadened half-widths for the 22.24- and 183.31-GHz lines derived using ground-based radiometric measurements and MonoRTM, a microwave radiative transfer model, agree within quoted errors with new values from CRB calculations by R. R. Gamache. For the derivation of the widths using radiometric measurements, the temperature dependences from the CRB were used rather than those from HITRAN. For the 22-GHz line, the measurements were from the MWRP, situated at the ARM SGP site in central Oklahoma. Atmospheric conditions at this site are favorable for investigation of the 


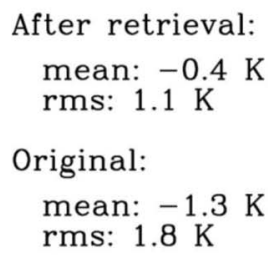

After retrieval:

mean: $-0.4 \mathrm{~K}$ rms: $1.1 \mathrm{~K}$

Original:

mean: $-1.3 \mathrm{~K}$ rms: $1.8 \mathrm{~K}$

\author{
After retrieval: \\ mean: $-0.3 \mathrm{~K}$ \\ rms: $1.3 \mathrm{~K}$

\section{Original:} \\ mean: $-0.8 \mathrm{~K}$ \\ rms: $2.1 \mathrm{~K}$
}

\section{After retrieval: mean: $0.0 \mathrm{~K}$ rms: $0.2 \mathrm{~K}$ \\ Original: mean: $0.7 \mathrm{~K}$ rms: $1.5 \mathrm{~K}$}

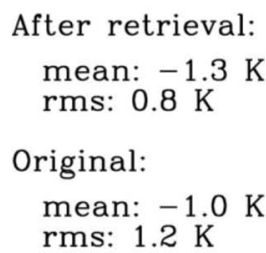

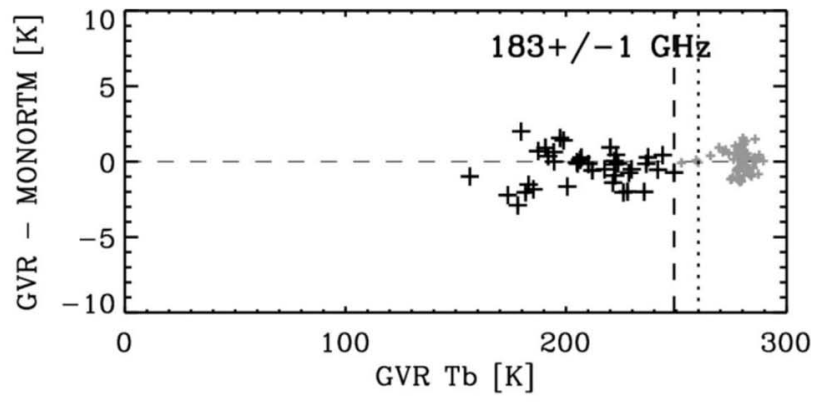
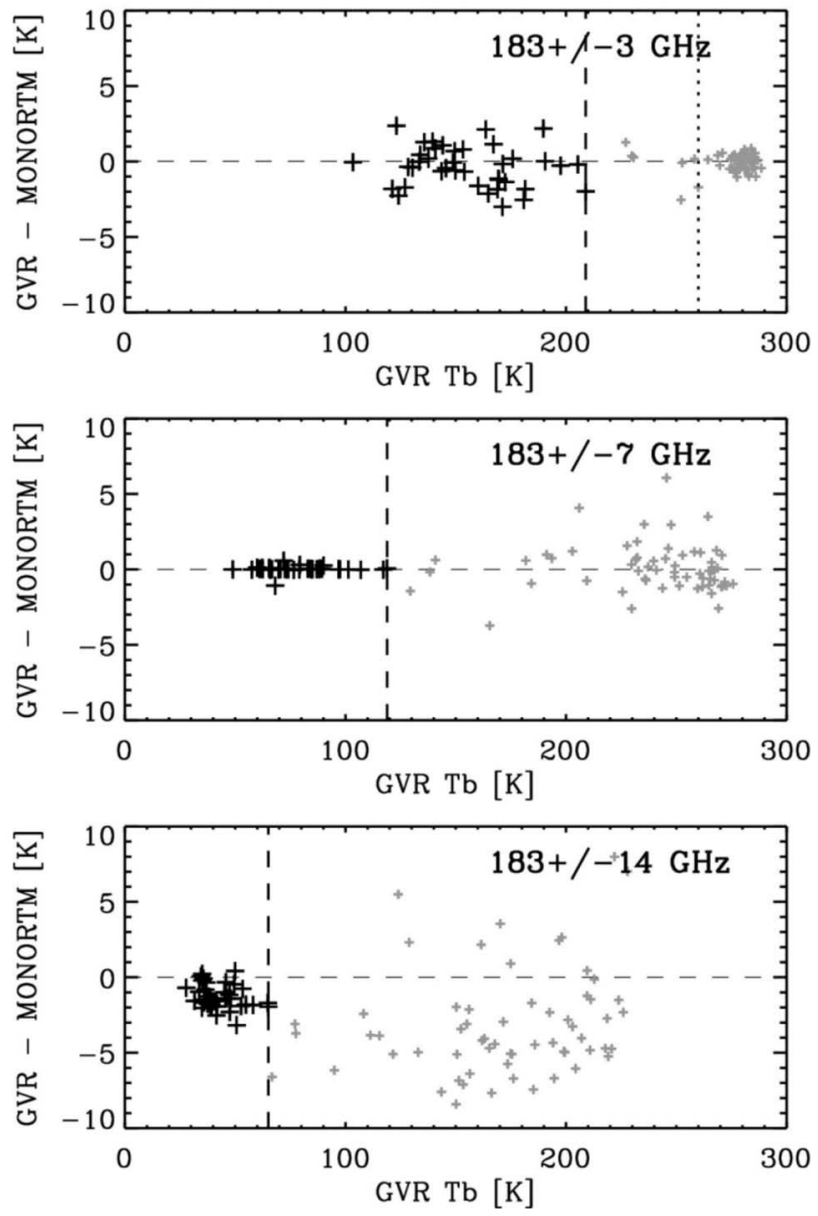

Fig. 12. Model/measurement brightness temperature differences in the GVR channels after the application of offsets and retrievals of PWV scaling factors and linewidth. The mean and rms around the mean are shown. Dotted vertical lines at $260 \mathrm{~K}$ in the $183 \pm / 1-$ and $\pm 3-\mathrm{GHz}$ plots show the brightness temperature cutoff used in the determination of the offset for these channels. Dashed vertical lines (all channels) show the position of the last data point that falls below the $120 \mathrm{~K}$ cutoff for the \pm 7 channel. No PWV retrieval was performed for points above this threshold. Quoted mean and rms values show the statistics for all points at brightness temperatures below the vertical dashed line. "Original" values quoted are the equivalent statistics for this subset of points in the raw comparison shown in Fig. 9 (left column).

22-GHz line. The value of the air-broadened half-width of the $22-\mathrm{GHz}$ line retrieved using this data has an estimated uncertainty of $1.6 \%$ and is within $1.4 \%$ of the value from the calculations by R. R. Gamache. The results of this paper indicate that the width used in the Rosenkranz model is too high, supporting the conclusions of Liljegren et al. (2005) [29]. The 22-GHz width value derived from measurements $0.0900 \mathrm{~cm}^{-1} / \mathrm{atm}$ will be used in future versions of MonoRTM with the temperature dependence from the CRB calculations. For the 183-GHz line, the measurements were from the GVR, an instrument situated at the ARM NSA site, near Barrow, AK. Conditions at this site are extremely dry, making these measure- ments suitable for studies of the $183-\mathrm{GHz}$ line, which would be saturated under SGP conditions. The width value for the $183-\mathrm{GHz}$ line is particularly important for studies of PWV and CLW, given that channels on the inner side of the "pivot point" of the line saturate at low water-vapor amounts. The value of the air-broadened half-width of the $183-\mathrm{GHz}$ line retrieved using the GVR data has an estimated uncertainty of $2.4 \%$ and is within $0.5 \%$ of the value from the Gamache CRB calculations. The CRB width value and temperature dependence for the $183 \mathrm{GHz}$ will be adopted in future versions of MonoRTM. The results of this paper will be considered for the next edition of HITRAN [26]. 
TABLE V

ERROR CONTRIBUTIONS FOR THE 183-GHz LINEWIDTH RETRIEVAL

\begin{tabular}{|l|c|}
\hline Error source & Contribution \\
\hline Random retrieval error & $0.1 \%$ \\
\hline $1 \mathrm{~K}$ temperature uncertainty & $0.3 \%$ \\
\hline $3 \%$ continuum uncertainty & $0.6 \%$ \\
\hline $10 \%$ column ozone uncertainty & $0.02 \%$ \\
\hline $1.5 \%$ PWV uncertainty & $1.5 \%$ \\
\hline $0.5 \%$ intensity uncertainty & $0.25 \%$ \\
\hline Water vapor profile shape uncertainty & $0.4 \%$ \\
\hline $1 \mathrm{~K}$ instrument calibration uncertainty & $1.6 \%$ \\
\hline Total & $\mathbf{2 . 4 \%}$ \\
\hline
\end{tabular}

\section{ACKNOWLEDGMENT}

The authors would like to thank the work done by S. Boukabara in developing MonoRTM and performing extensive sensitivity studies. Any opinions, findings, and conclusions or recommendations expressed in this material are those of the authors and do not necessarily reflect the views of the National Science Foundation. The authors would also like to thank I. Gordon and L. Rothman for their constructive comments on this paper, as well as three anonymous reviewers for their insight and suggestions.

\section{REFERENCES}

[1] F. S. Solheim, J. R. Godwin, and R. Ware, "Passive, ground-based remote sensing of temperature, water vapor and cloud liquid profiles by a frequency-synthesized microwave radiometer," Meteorol. Z., vol. 7, pp. 370-376, 1998.

[2] P. E. Racette, E. R. Westwater, Y. Han, A. J. Gasiewski, M. Kein, D. Cimini, D. C. Jones, W. Manning, E. J. Kim, J. R. Wanf, V. Leuski, and P. Kiedron, "Measurement of low amounts of precipitable water vapor using ground-based millimeterwave radiometry," J. Atmos. Ocean. Technol., vol. 22, no. 4, pp. 317-337, Apr. 2005.

[3] D. Cimini, E. Westwater, A. Gasiewski, M. Klein, V. Leuski, and S. Dowlatshahi, "The ground-based scanning radiometer: A powerful tool for study of the Arctic atmosphere," IEEE Trans. Geosci. Remote Sens., vol. 45, no. 9, pp. 2759-2777, Sep. 2007.

[4] M. P. Cadeddu, J. C. Liljegren, and A. Pazmany, "Measurements and retrievals from a new $183-\mathrm{GHz}$ water vapor radiometer in the Arctic," IEEE Trans. Geosci. Remote Sens., vol. 45, no. 7, pp. 2207-2215, Sep. 2007

[5] J. R. Wang, P. Racette, M. E. Triesky, E. V. Browell, S. Ismail, and L. A. Chang, "Profiling of atmospheric water vapor with MIR and LASE," IEEE Trans. Geosci. Remote Sens., vol. 40, no. 6, pp. 1211-1219, Jun. 2002.

[6] B. Deuber, N. Kaempfer, and D. G. Feist, "A new 22-GHz radiometer for middle atmospheric water vapor profile measurements," IEEE Trans. Geosci. Remote Sens., vol. 42, no. 5, pp. 974-984, May 2004.

[7] V. Vasic, D. G. Feist, S. Muller, and N. Kaempfer, "An airborne radiometer for stratospheric water vapor measurements at $183 \mathrm{GHz}$," IEEE Trans. Geosci. Remote Sens., vol. 43, no. 7, pp. 1563-1570, Jul. 2005.

[8] P. Schluessel and W. J. Emery, "Atmospheric water vapour over oceans from SSM/I measurements," Int. J. Remote Sens., vol. 11, no. 5, pp. 753766, May 1990.

[9] P. W. Rosenkranz, "Retrieval of temperature and moisture profiles from AMSU-A and AMSU-B measurements," IEEE Trans. Geosci. Remote Sens., vol. 39, no. 11, pp. 2429-2435, Nov. 2001.

[10] T. Kawanishi, T. Sezai, Y. Ito, K. Imaoka, T. Takeshima, Y. Ishido, A. Shibata, M. Miura, H. Inahata, and R. W. Spencer, "The Advanced Microwave Scanning Radiometer for the Earth Observing System (AMSR-E), NSADA's contribution to the EOS for global energy and water cycle studies," IEEE Trans. Geosci. Remote Sens., vol. 41, no. 2, pp. 184-194, Feb. 2003.

[11] D. D. Turner, B. M. Lesht, S. A. Clough, J. C. Liljegren, H. E. Revercomb, and D. C. Tobin, "Dry bias and variability in Vaisala RS80-H radiosondes: The ARM experience," J. Atmos. Ocean. Technol., vol. 20, no. 1, pp. 117132, Jan. 2003.
[12] C. Lucas and E. J. Zipser, "Environmental variability during TOGA COARE," J. Atmos. Sci., vol. 57, no. 15, pp. 2333-2350, Aug. 2000.

[13] L. M. Miloshevich, H. Vömel, D. N. Whiteman, B. M. Lesht, F. J. Schmidlin, and F. Russo, "Absolute accuracy of water vapor measurements from six operational radiosonde types launched during AWEX-G and implications for AIRS validation," J. Geophys. Res., vol. 111, no. D09, p. D09 S10, Apr. 2006.

[14] H. Vömel, H. Selkirk, L. Miloshevich, J. Valverde, J. Valdés, E. Kyrö, R. Kivi, W. Stolz, G. Peng, and J. A. Diaz, "Radiation dry bias of the Vaisala RS92 humidity sensor," J. Atmos. Ocean. Technol., vol. 24, no. 6, pp. 653-863, Jun. 2007.

[15] K. E. Cady-Pereira, M. W. Shephard, D. D. Turner, E. J. Mlawer, S. A. Clough, and T. J. Wagner, "Improved daytime column-integrated precipitable water vapor from Vaisala radiosonde humidity sensors," J. Atmos. Ocean. Technol., vol. 25, no. 6, pp. 873-883, Jun. 2008.

[16] S. A. Boubakara, S. A. Clough, and R. N. Hoffman, "MonoRTM: A monochromatic radiative transfer model for microwave and laser calculations," in Proc. 22nd Annu. Rev. Atmos. Transmittance Models, Hanscom AFB, MA, Jun. 1999.

[17] S. A. Clough, M. W. Shephard, E. Mlawer, J. S. Delamere, M. Iacono, K. E. Cady-Pereira, S. Boukabara, and P. D. Brown, "Atmospheric radiative transfer modeling: A summary of the AER codes," J. Quant. Spectrosc. Radiat. Transf., vol. 91, no. 2, pp. 233-244, Mar. 2005.

[18] J. Humlicek, "Optimized computation of the Voigt and complex probability functions," J. Quant. Spectrosc. Radiat. Transf., vol. 27, no. 4, pp. 437-444, Apr. 1982.

[19] M. Y. Tretyakov, M. A. Koshelev, V. V. Dorovskikh, D. S. Makarov, and P. W. Rosenkranz, "60-GHz oxygen band: Precise broadening and central frequencies of fine-structure lines, absolute absorption profile at atmospheric pressure, and revision of mixing-coefficients," J. Mol. Spectrosc., vol. 231, no. 1, pp. 1-14, May 2005.

[20] M. P. Cadeddu, V. H. Payne, S. A. Clough, K. E. Cady-Pereira, and J. C. Liljegren, "Effect of the oxygen line parameter modeling on temperature and humidity retrievals from ground-based microwave radiometers," IEEE Trans. Geosci. Remote Sens., vol. 45, no. 9, pp. 22162223, Sep. 2007.

[21] S. A. Clough, Y. Beers, J. P. Klein, and L. S. Rothman, "Dipole moment of water from Stark measurements of $\mathrm{H}_{2} \mathrm{O}, \mathrm{HDO}$ and $\mathrm{D}_{2} \mathrm{O}$," J. Chem. Phys., vol. 59, pp. 2254-2259, Sep. 1973.

[22] G. E. Becker and S. H. Autler, "Water vapor absorption of electromagnetic radiation in the centimeter wave-length range," Phys. Rev., vol. 70, no. 5/6, pp. 300-307, Sep. 1946.

[23] H. J. Liebe and T. A. Dillon, "Accurate foreign-gas broadening parameters of the 22- $\mathrm{GHz} \mathrm{H}_{2} \mathrm{O}$ line from refraction spectroscopy," J. Chem. Phys., vol. 50, pp. 727-732, 1969.

[24] D. Mrowonski, "Refraction and absorption in atmospheric gases near the $22 \mathrm{GHz}$ water vapour rotational line," Z. Angew. Phys., vol. 29, pp. 323-330, 1970.

[25] L. S. Rothman, A. Barbe, D. C. Benner, L. R. Brown, C. Camy-Peyret, M. R. Carleer, K. Chance, C. Clerbaux, V. Dana, V. M. Devi, A. Fayt, J.-M. Flaud, R. R. Gamache, A. Goldman, D. Jacquemart, K. W. Jucks, W. J. Lafferty, J.-Y. Mandin, S. T. Massie, V. Nemtchinov, D. A. Newnham, A. Perrin, C. P. Rinsland, J. Schroeder, K. M. Smith, M. A. H. Smith, K. Tang, R. A. Toth, J. Vander Auwera, P. Varanasi, and K. Yoshino, "The HITRAN molecular spectroscopic database: Edition of 2000 including updates through 2001," J. Quant. Spectrosc. Radiat. Transf., vol. 82, no. 1, pp. 5-44, Nov. 2003.

[26] L. S. Rothman, D. Jacquemart, A. Barbe, D. C. Benner, M. Birk, L. R. Brown, M. R. Carleer, C. Chackerian, K. Chance, L. H. Coudert, V. Dana, V. M. Devi, J.-M. Flaud, R. R. Gamache, A. Goldman, J.-M. Hartmann, K. W. Jucks, A. G. Maki, J. Y. Mandin, S. T. Massie, J. Orphal, A. Perrin, C. P. Rinsland, M. A. H. Smith, J. Tennyson, R. N. Tolchenov, R. A. Toth, J. Vander Auwera, P. Varanasi, and G. Wagner, "The HITRAN 2004 molecular spectroscopic database," $J$. Quant. Spectrosc. Radiat. Transf., vol. 96, no. 2, pp. 139-204, Dec. 2005.

[27] I. E. Gordon, L. S. Rothman, R. R. Gamache, D. Jacquemart, C. Boone, P. F. Bernath, M. Shephard, J. S. Delamere, and S. A. Clough, "Current updates of water vapor line list in HITRAN 2004: A new 'Diet' for airbroadened half-widths," J. Quant. Spectrosc. Radiat. Transf., vol. 108, no. 3, pp. 389-402, Dec. 2007

[28] G. Cazzoli, C. Puzzarini, G. Buffa, and O. Tarrini, "Experimental and theoretical investigation on pressure-broadening and pressure-shifting of the $22.2 \mathrm{GHz}$ line of water," J. Quant. Spectrosc. Radiat. Transf., vol. 105, no. 3, pp. 438-449, Jul. 2007.

[29] P. W. Rosenkranz, "Water vapor microwave continuum absorption: A comparison of measurements and models," Radio Sci., vol. 33, no. 4, pp. 919-928, Jul. 1998. 
[30] P. W. Rosenkranz and C. D. Barnet, "Microwave radiative transfer model validation," J. Geophys. Res., vol. 111, no. D9, p. D09 S07, Mar. 2006.

[31] J. C. Liljegren, S. A. Boukabara, K. Cady-Pereira, and S. A. Clough, "The effect of the half-width of the 22-GHz water vapor line on retrievals of temperature and water vapor profiles with a 12-channel microwave radiometer," IEEE Trans. Geosci. Remote Sens., vol. 43, no. 5, pp. 11021108, May 2005.

[32] J. R. Rusk, "Temperature and Zeeman measurements on the 1.64-mm $\mathrm{H}_{2} \mathrm{O}$ absorption line," J. Chem. Phys., vol. 43, no. 8, pp. 2919-2920, Oct. 1965.

[33] L. Frenkel and D. Woods, "Microwave absorption by $\mathrm{H}_{2} \mathrm{O}$ vapor and its mixtures with other gases between 100 and $300 \mathrm{GC} / \mathrm{S}$," Proc. IEEE, vol. 54, no. 4, pp. 498-505, Apr. 1966.

[34] C. O. Hemmi and A. W. Straiton, "Pressure broadening of 1.63-mm water vapor absorption line," Radio Sci., vol. 4, pp. 9-15, Jan. 1969.

[35] V. Y. Ryadov and N. I. Furashov, "Concerning the widths and intensities of submillimeter absorption lines of the rotational spectrum of water vapor," Radiophys. Quantum Electron., vol. 18, no. 3, pp. 256266, Mar. 1975.

[36] A. Bauer, M. Godon, and B. Duterage, "Self- and air-broadened linewidth of the $183 \mathrm{GHz}$ absorption in water vapor," J. Quant. Spectrosc. Radiat. Transf., vol. 33, no. 2, pp. 167-175, Feb. 1985.

[37] A. Bauer, M. Godon, M. Kheddar, and J.-M. Hartmann, "Temperature and perturber dependences of water vapor line-broadening. Experiments at $183 \mathrm{GHz}$; calculations below $1000 \mathrm{GHz}$," J. Quant. Spectrosc. Radiat. Transf., vol. 41, no. 1, pp. 49-54, Jan. 1989.

[38] T. M. Goyette and F. C. De Lucia, "The pressure broadening of the $3_{1,3}-2_{2,0}$ transition of water between 80 and $600 \mathrm{~K}$," J. Mol. Spectrosc., vol. 143, no. 2, pp. 346-358, Oct. 1990.

[39] M. Y. Tretyakov, V. V. Parshin, M. A. Koshelev, V. N. Shanin, S. E. Myasnikova, and A. F. Krupnov, "Studies of $183 \mathrm{GHz}$ water line: Broadening and shifting by air, $\mathrm{N}_{2}$ and $\mathrm{O}_{2}$ and integral intensity measurements," J. Mol. Spectrosc., vol. 218, no. 2, pp. 239-245, Apr. 2003.

[40] G. Y. Golubiatnikov, "Shifting and broadening parameters of the water vapor $183-\mathrm{GHz}$ line $\left(3_{13}-2_{20}\right)$ by $\mathrm{H}_{2} \mathrm{O}, \mathrm{O}_{2}, \mathrm{~N}_{2}, \mathrm{CO}_{2}, \mathrm{H}_{2}, \mathrm{He}, \mathrm{Ne}$, $\mathrm{Ar}$, and $\mathrm{Kr}$ at room temperature," J. Mol. Spectrosc., vol. 230, no. 2, pp. 196-198, Apr. 2005.

[41] S. L. Cruz-Pol, C. S. Ruf, and S. J. Keihm, "Improved $22-32 \mathrm{GHz}$ atmospheric absorption model," Radio Sci., vol. 33, no. 5, pp. 1319-1333, Jun. 1998.

[42] H. C. Pumphrey and S. Buehler, "Instrumental and spectral parameters: Their effect on and measurement by microwave limb sounding of the atmosphere," J. Quant. Spectrosc. Radiat. Transf., vol. 64, no. 4, pp. 421-437, Jul. 2000.

[43] A. L. Pazmany, "An operational G-band $(183 \mathrm{GHz})$ water vapor radiometer," IEEE Trans. Geosci. Remote Sens., vol. 45, no. 7, pp. 2202-2206, Sep. 2007.

[44] G. Anderson, S. A. Clough, F. X. Kneizys, J. H. Chetwynd, and E. P. Shettle, "AFGL atmospheric constituent profiles $(0-120 \mathrm{~km})$," in Optical Physics Division, Project 760. Hanscom AFB, MA: Air Force Geophys. Lab., May 1986.

[45] S. A. Clough, E. E. Clothiaux, K. Cady-Pereira, S. Boukabara, J. C. Liljegren, and D. D. Turner, "Physical retrievals of PWV and CLW from ARM microwave radiometers," in Proc. XIIIth ARM Sci. Team Meeting, Broomfield, CO, Apr. 2003.

[46] C. D. Rodgers, Inverse Methods for Atmospheric Sounding: Theory and Practice. Singapore: World Scientific, 2000.

[47] D. Robert and J. Bonamy, "Short range force effects in semiclassical molecular line broadening calculations," J. Phys. Paris, vol. 40, pp. $923-$ 943, 1979.

[48] R. R. Gamache, R. Lynch, and S. P. Neshyba, "New developments in the theory of pressure-broadening and pressure-shifting of spectral lines of $\mathrm{H}_{2} \mathrm{O}$ : The complex Robert-Bonamy formalism," J. Quant. Spectrosc. Radiat. Transf., vol. 59, no. 3, pp. 319-335, Mar. 1998.

[49] R. Lynch, R. R. Gamache, and S. P. Neshyba, " $\mathrm{N}_{2}$ and $\mathrm{O}_{2}$ induced halfwidths and line shifts of water vapor transitions in the $(301) \leftarrow(000)$ and $(221) \leftarrow(000)$ Bands," J. Quant. Spectrosc. Radiat. Transf., vol. 59, no. 6, pp. 595-613, Jun. 1998

[50] M. Baranger, "General impact theory of pressure broadening," Phys. Rev., vol. 112 , no. 3, pp. 855-865, Nov. 1958.

[51] A. Ben-Reuven, "Spectral line shapes in gases in the binary collision approximation," in Advances in Chemical Physics, vol. 33, I. Prigogine and S. A. Rice, Eds. New York: Wiley, 1975, pp. 235-293.

[52] R. Lynch, "Half-widths and line shifts of water vapor perturbed by both nitrogen and oxygen," Ph.D. dissertation, Phys. Dept., Univ. Massachusetts Lowell, Lowell, MA, 1995.
[53] S. P. Neshyba and R. R. Gamache, "Improved line-broadening coefficients for asymmetric rotor molecules with application to ozone lines broadened by nitrogen," J. Quant. Spectrosc. Radiat. Transf., vol. 50, no. 5, pp. 443453, Nov. 1993.

[54] J. E. Jones, "On the determination of molecular fields. II. From the equation of state of a gas," Proc. R. Soc. Lond. A, Math. Phys. Sci., vol. 106, no. 738 , pp. 463-477, Oct. 1924

[55] J. O. Hirschfelder, C. F. Curtiss, and R. B. Bird, Molecular Theory of Gases and Liquids. Hoboken, NJ: Wiley, 1964.

[56] R. A. Sack, "Two-center expansion for the powers of the distance between two points," J. Math. Phys., vol. 5, pp. 260-268, 1964.

[57] J. K. G. Watson, "Determination of centrifugal distortion coefficients of asymmetric-top molecules," J. Chem. Phys., vol. 46, no. 5, pp. 19351949, Mar. 1967.

[58] F. Matsushima, H. Odashima, T. Iwaskai, and S. Tsunekawa, "Frequency measurement of pure rotational transitions of $\mathrm{H}_{2} \mathrm{O}$ from 0.5 to $5 \mathrm{THz}$," J. Mol. Struct., vol. 352, pp. 371-378, Jun. 1995.

[59] R. R. Gamache, "Line shape parameters for water vapor in the 3.2 to $17.76 \mu \mathrm{m}$ region for atmospheric applications," J. Mol. Spectrosc., vol. 229 , no. 1, pp. 9-18, Jan. 2005.

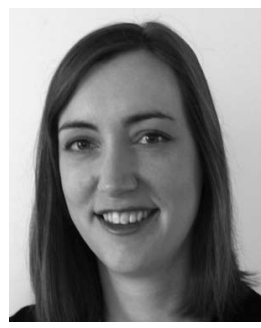

Vivienne H. Payne received the M.Phys. degree in physics from the University of Edinburgh, Edinburgh, U.K., in 2001, and the D.Phil. degree in atmospheric physics from the University of Oxford, Oxford, U.K., in 2005, where she worked on retrievals of water vapor and methane from Michelson Interferometer for Passive Atmospheric Sounding, an infrared limb sounder flying on European Space Agency's Envisat satellite.

She spent part of 2005 with the University of Colorado, Boulder, working on the interpretation of her retrievals of water-vapor isotopes before joining Atmospheric and Environmental Research, Inc., Lexington, MA, in January 2006. Her principal areas of interest include atmospheric radiative transfer modeling, spectroscopy, and retrievals in the infrared and microwave regions.

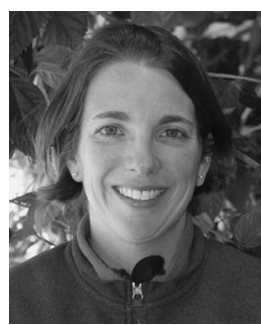

Jennifer S. Delamere received the B.A. degree in Physics from John Hopkins University in 1993 and the Ph.D. degree in Physics from the University of Alaska, Fairbanks, in 2003.

She has been employed as a Staff Scientist with Atmospheric and Environmental Research, Inc. (AER), Lexington, MA, since 2000. Her research is focused on the validation and improvement of atmospheric radiative transfer models, from line-byline to general circulation model-appropriate models. She has been involved with the Department of Energy's Atmospheric Radiation Measurement (ARM) Program in a variety of capacities over the last 14 years, participating in ARM-sponsored measurement campaigns and undertaking radiative closure studies between AER's radiative transfer models and ARM Climate Research Facility data. She currently resides in Boulder, $\mathrm{CO}$, and is a Guest Scientist with the National Oceanic and Atmospheric Administration Earth System Research Laboratory/Global Monitoring Division.

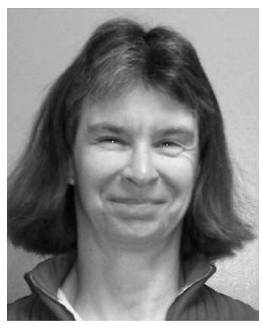

Karen E. Cady-Pereira received the degree in physics from the University of Sao Paulo, Sao Paulo, Brazil, in 1980, and the M.S. degree in oceanography from Massachusetts Institute of Technology, Cambridge, in 1984.

She has been with Atmospheric and Environmental Research, Inc., Lexington, MA, for 15 years, where she was first with the General Circulation group and has been with the Remote Sensing and Radiation and Climate groups since 1994. She has worked on radiative transfer problems across the entire spectrum, from determining bidirectional reflectance distribution function from multiangle imaging spectroradiometer measurements to measuring atmospheric water vapor using microwave radiometers. She is particularly interested in scattering from surfaces (such as icy planets or vegetated land) and from particles in the atmosphere. 


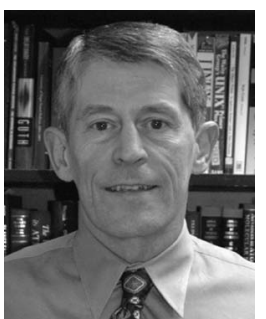

Robert R. Gamache received the Baccalaureate degree from the University of Massachusetts, Dartmouth, and the graduate degrees from the University of Massachusetts, Amherst.

$\mathrm{He}$ is currently with the Department of Environmental, Earth, and Atmospheric Sciences, University of Massachusetts, Lowell. He has been a member of the faculty since 1978, where he served as an active Researcher, Teacher, and an Administrator with the Center for Atmospheric Research. He also has a long-standing relationship with universities in France. He has had eight invited professorships since 1990, and he spent his 2002 sabbatical leave as a Centre National de la Recherche Scientifique Research Associate with the Laboratory of Molecular Photo-Physics, University of Paris-South, Paris, France. He has presented over 135 papers at professional conferences, published 92 articles in refereed journals, published over 50 scientific reports, and has presented numerous invited lectures in the U.S. and Europe. He is currently Principle Investigator for more than $\$ 300000$ in federal grants, with over $\$ 4$ million in external funding received to date. His fields of expertise include the interaction of radiation with matter, and chemistry and physics of atmospheres with particular application to remote sensing. His current work involves Aqua and Aura satellite programs of NASA's Earth Observing System, remote-sensing missions to Mars and Venus, and several satellite programs of European Space Agency, European Organisation for the Exploitation of Meteorological Satellites, and Centre National d'Etudes Spatiales.

Prof. Gamache was the corecipient of the 1998 Sir Harold Thompson Memorial Award, which is presented by Pergamon Journals, Ltd., to the authors of the paper that makes the most significant contribution to spectroscopy.

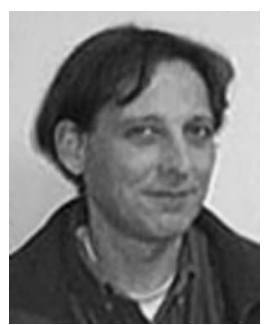

Jean-Luc Moncet received the Engineering degree in applied physics from Ecole Nationale Superieure de Physique, Marseilles, France, in 1981, the MSc degree in telecommunications from Institut National de la Recherche Scientifique (INRS), Quebec City, QC, in Canada, in 1984 and the M.Sc. degree in meteorology from McGill University, Montreal, QC, Canada in 1989.

$\mathrm{He}$ is Head of the Remote Sensing Programs with Atmospheric and Environmental Research, Inc. (AER), Lexington, MA, which oversees the activities of the Infrared, Microwave, Trace gases and Cloud remote-sensing groups. During his accumulated 16 years of experience in infrared, microwave, and UV remote sensing and radiative transfer modeling, he has led the environmental data record (EDR) algorithm development for both infrared and microwave instruments on the National Polar-orbiting Operational Satellite System. He is Codeveloper of the Unified Retrieval concept, currently used in the Crosstrack Microwave Scanner, Advanced Microwave Sounding Unit, Cross-track Infrared Sounder, and Ozone Mapping and Profiler Suite EDR algorithms, and participated to the Special Sensor Microwave Temperature-2 and Special Sensor Microwave Image/Sounder cal/val effort. Since joining AER, he has developed high speed, high spectral resolution radiative transfer algorithms (including the Optimal Spectral Sampling method (U.S. Patent) and the Code for High-Resolution Atmospheric Radiative Transfer with Scattering for monochromatic radiance calculations in scattering atmospheres) and inversion algorithms for application to space borne infrared down-looking and limb sensors, airborne and ground-based interferometers. He has also provided support to the aerospace industry for several instrument trade studies. Other areas of activity include cloud property retrievals from infrared spectrometric measurements and combined microwave/electrooptical imagers, numerical weather prediction model assimilation and radiation/climate studies.

Mr. Moncet is a member of the NASA Advanced Microwave Scanning Radiometer and Atmospheric Infrared Sounder science teams.

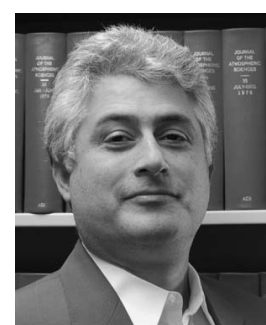

Eli J. Mlawer received the B.A. degree in mathematics and astronomy from Williams College, Williamstown, MA, in 1982, the B.A. and M.A. degrees in physics from Cambridge University, Cambridge, MA, in 1984 and 1990, respectively, and the $\mathrm{Ph} . \mathrm{D}$. degree in physics from Brandeis University, Waltham, MA, in 1994.

Since then, he has been with Atmospheric and Environmental Research, Inc., Lexington, MA, where he is the Manager of the Radiation and Climate Group. His research interests are in atmospheric radiative transfer, climate study, and the characterization of molecular collisional broadening. He has primary responsibility for the design, implementation, and validation of rapid radiative transfer model (RRTM), a radiative transfer model for climate applications used by many climate and weather prediction models. He is a participant in the research being conducted with a number of climate models utilizing RRTM, and continues to actively partake in the Intercomparison of Radiation Codes in Climate Models effort. As part of his involvement in the Department of Energy's Atmospheric Radiation Measurement (ARM) Program, he is the focus group leader of the Broadband Heating Rate Profile project, an effort to compute fluxes and heating rates in clear and cloudy conditions at the ARM sites and to perform a closure analysis on these calculations using surface and top of atmosphere radiation measurements. $\mathrm{He}$ was Coprincipal Investigator of the Radiative Heating in Underexplored Bands Campaign, an ARM field experiment directed at increasing our understanding of radiative processes in the far-infrared spectral region of importance to climate. This campaign took place in northern Alaska in early 2007, and a second more intensive follow-up experiment is planned for Chile in 2009. $\mathrm{He}$ is the Developer of the MT_CKD water-vapor continuum model, a key component in the majority of existing atmospheric radiative transfer models.

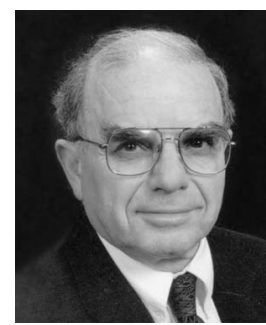

Shepard A. Clough received the B.S. degree in engineering physics from Cornell University, Ithaca, NY, in 1954 and the Masters degree from Columbia University, New York, NY, in 1957.

$\mathrm{He}$ was then with the Air Force Geophysics Laboratory (AFGL), conducting research on the molecular spectroscopy of atmospheric molecules, principally water vapor and ozone. His education continued at the Massachusetts Institute of Technology, Cambridge. He has recently been elected Fellow of the American Meteorological Society. Following an extended career at AFGL, he accepted a position with Atmospheric and Environmental Research, Inc., Lexington, MA, where he led the Radiation and Climate Group. He is a Participant in the Earth Observing System (EOS) project as a Coinvestigator on the tropospheric emission spectrometer (TES), a high-resolution spectrometer on the EOS AURA platform. He is a member of the Science Team of the Atmospheric Radiation Measurement Program, researching on the development, improvement, and validation of radiative transfer models and atmospheric composition. He has been responsible for the development of the widely used atmospheric radiative modeling codes including line-by-line radiative transfer model, rapid radiative transfer model, and Code for High-Resolution Atmospheric Radiative Transfer with Scattering and has made significant contributions to the High-resolution Transmission Molecular Absorption spectroscopic database. He is well known for his contributions to the theory of collision broadening as applied to atmospheric problems including the water-vapor continuum. His principal areas of interest include atmospheric radiative transfer, molecular physics, and approaches to the retrieval of information from remotely sensed measurements. His current activities are focused on the improvement of radiative transfer modeling with application to remote sensing and to general circulation models for climate change studies and include the assessment of the forward model used by TES and its improvement. 